\title{
DART: A 3D Model for Remote Sensing Images and Radiative Budget of Earth Surfaces
}

\author{
J.P. Gastellu-Etchegorry, E. Grau and N. Lauret \\ CESBIO - CNES, CNRS (UMR 5126), IRD, Université de Toulouse, Toulouse, \\ France
}

\section{Introduction}

Knowledge of the radiative behavior and the energy budget of land surfaces is essential for studying the functioning of natural and urban surfaces with remotely acquired information. Account of their 3D nature is often essential because in most cases these surfaces are not isotropic. For example, it has long been known that the albedo of a canopy with anisotropic Bi-directional Reflectance Factors (BRF) may be underestimated by as much as $45 \%$ if it is computed with nadir reflectance only (Kimes and Sellers, 1985). Radiative transfer (R.T.) models have the potential for correcting this type of error provided they account for the three dimensional (3D) nature of Earth surfaces. Neglect of the $3 \mathrm{D}$ structure of canopies can lead to large errors on the 3D radiation budget and remote sensing measurements. For example, for vegetation BRF and directional brightness temperature (DTDF) distribution functions, errors can be as large as $50 \%$, depending on instrumental (e.g., view and sun directions) and experimental (e.g., vegetation heterogeneity) conditions (Gastellu-Etchegorry et al., 1999). The problem is similar for urban canopies due to their strong spatial heterogeneity. The application of R.T. modeling to urban surfaces is important in the context of the advent of satellite sensors with spatial and spectral resolutions that are more and more adapted to urban characteristics such as building dimensions and temperature spatial variability. It explains the numerous works conducted in the field of remote sensing of urban surfaces (Soux et al., 2004; Voogt and Oke, 1998). The use of descriptions with qualitatively based land use data instead of more fundamental surface descriptors is a source of inaccuracy for modeling BRFs and DTDFs (Voogt and Oke, 2003).

R.T. models are essential tools for assessing accurately radiative quantities such as the exitance, the irradiance and remote sensing measurements in the optical and thermal domains. However, in order to meet this objective, models must account for the three dimensional (3D) nature of Earth surfaces. Here, we consider vegetation canopies and urban canopies. This consideration of the 3D architecture of Earth surfaces is possible with the socalled 3D models. Generally speaking, the latter ones are intended to be accurate, robust and more comprehensive than other models. Ideally, they should be used in place of other models. However, they are often more difficult to manage, both in terms of computation 
time and landscape description. Moreover, when dealing with specific situations, one needs that the model be accurate and robust, but one does not necessarily need that the model be comprehensive. This explains that in many cases, the objective of 3D models is to calibrate models that are simpler to manage in terms of landscape description, computation time, etc. Once calibrated, these models can meet the required accuracy levels.

These remarks stress the usefulness of 3D R.T. models. A number of 3D models is being developed by the scientific community (Widlowski et al., 2007). Usually, they are designed for a given type of landscape (e.g., natural or urban), with or without topography and atmosphere, for a specific type of application (e.g., remote sensing or radiation budget), and for a given spatial resolution of analysis (e.g., simulation of a tree crown with or without branches). Moreover, remote sensing models are usually designed for a given spectral domain (e.g., sun reflected spectral domain or thermal infrared spectral domain).

A common problem when designing a R.T. model is to assess to which level of detail landscapes must be taken into account. This is very especially important in term of landscape simulation. However, it affects also the mathematical formulation of R.T. Generally speaking, one should take into account all landscape elements that have a significant influence on the application we are dealing with (i.e., landscape radiative budget or remote sensing measurement). In practice, the answer can be complex. For example, when simulating remote sensing measurements of heterogeneous Earth surfaces in the visible spectral domain, is it necessary to simulate the atmosphere within a unique "Earth Atmosphere" system in order to simulate with a good accuracy its complex interaction with earth surfaces?

Some of these aspects are discussed here with the brief presentation of DART (Discrete Anisotropic Radiative Transfer) model. This is one of the most complete 3D models designed for simulating the radiative budget and the satellite observations of the land surfaces in the visible, near infrared and thermal infrared of land surfaces. It was originally developed (Gastellu-Etchegorry et al., 1996) for simulating remote sensing images of 3D vegetation canopies in the visible / near infrared (NIR) spectral domain. Afterwards, it was extended to the thermal infrared domain and to the simulation of any landscape: urban or natural, with atmosphere and topography. As a result, the present DART model simulates the radiation budget and remote sensing images of vegetation and urban canopies, for any experimental (sun direction, canopy heterogeneity, topography, atmosphere, etc.) and instrumental (view direction, spatial resolution, etc.) configuration.

After a brief presentation of DART, two types of applications are discussed: urban and forest canopies. This is followed by the presentation of three recent improvements:

- Account of the Earth / Atmosphere curvature for oblique remote sensing measurements.

- Possibility to import 3D objects simulated as the juxtaposition of triangles and to transform them into 3D turbid objects.

- Possibility to simulate landscapes that have a continuous topography and landscapes that are non repetitive.

Finally, preliminary results concerning two application domains are discussed. 1) 2D distributions of reflectance, brightness temperature and radiance of the African continent that would be measured by a geostationary satellite. 2) Radiative budget of urban (GastelluEtchegorry, 2008) and natural (Belot, 2007) canopies. They are simulated with a DART energy budget (EB) component, called DARTEB, under development. 


\section{DART model}

DART was originally developed for simulating BRFs (Bi-directionnal Reflectance Factor), remote sensing images and the spectral radiation budget of 3D natural (e.g., trees, roads, grass, soil, water) landscapes in the visible and short wave infrared domains. Since its first release in 1996, it was successfully tested, in the case of vegetation canopies, against reflectance measurements (Gastellu-Etchegorry et al., 1999) and against a number of 3-D reflectance models (e.g., Flight (North, 1996), Sprint (Thompson and Goel, 1998), Raytran (Govaerts and Verstraete, 1998)), in the context of the RAMI (RAdiation transfer Model Intercomparison) experiment (Pinty et al., 2001; Pinty et al., 2004; Widlowski et al., 2007; Widlowski et al., 2008). Only BRFs could be compared because DART was the only 3-D model that simulates images.

DART was successfully used in many scientific domains: impact of canopy structure on satellite images texture (Pinel and Gastellu-Etchegorry, 1998) and reflectance (GastelluEtchegorry et al., 1999), 3D distribution of photosynthesis and primary production rates of vegetation canopies (Guillevic and Gastellu-Etchegorry, 1999), influence of Norway forest spruce structure and woody elements on LAI retrieval (Malenovský et al., 2005) and canopy reflectance (Malenovský et al., 2008), determination of a new hyperspectral index for chlorophyll estimation of forest canopy (Malenovský et al., 2006), study of tropical forest texture (Barbier et. al., 2010; Barbier et. al., 2011; Proisy C. et al., 2011).

DART simulates R.T. in heterogeneous 3-D landscapes with the exact kernel and discrete ordinate methods. It uses an iterative approach: radiation intercepted in iteration " $\mathrm{i}$ " is scattered in iteration "i+1". Any landscape is simulated as a rectangular matrix of parallelepipedic cells. Figure 1 illustrates the way urban and natural landscapes are

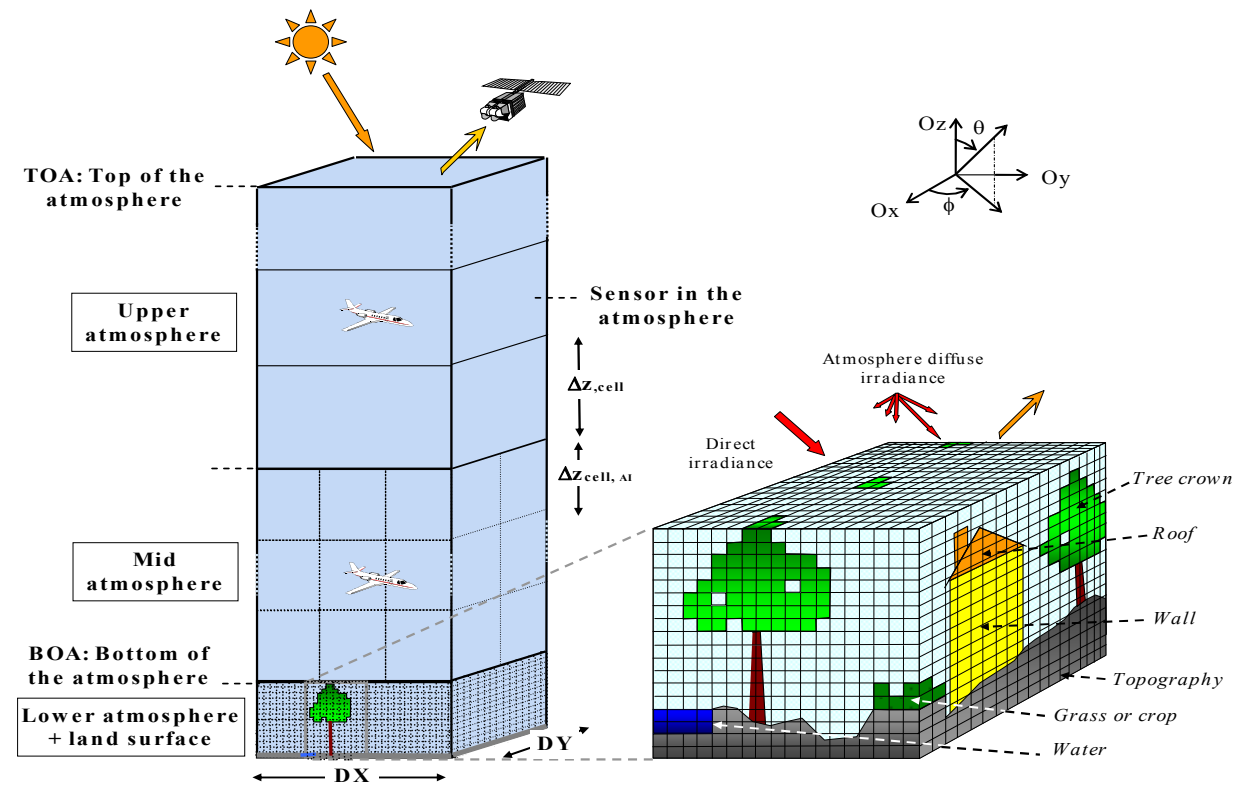

Fig. 1. DART cell matrix of the Earth / Atmosphere system. 
simulated, possibly with topography and atmosphere. The atmosphere is made of cells the size of which increases with altitude. Radiation is restricted to propagate in a finite number of directions $\left(\Omega_{\mathrm{i}}\right)$ with an angular sector width $\left(\Delta \Omega_{\mathrm{i}}\right)$ (sr). Any set of $\mathrm{N}$ discrete directions can be selected $\left(\sum_{n=1}^{N} \Delta \Omega_{\mathrm{n}}=4 \pi\right)$. A radiation that propagates along direction $\left(\Omega_{\mathrm{i}}\right)$ at a position $\mathrm{r}$ is called a source vector $\mathrm{W}\left(\mathrm{r}, \Omega_{\mathrm{i}}\right)$. It has 3 components: total radiation $\mathrm{W}$, radiation unrelated to leaf mesophyll and polarization degree associated to first order scattering.

The atmosphere has 3 levels: upper (i.e., layers with any depth), mid (i.e., cells with any size) and lower (i.e., cells identical to land surface cells) atmosphere. Land surface elements are the juxtaposition of triangles and/or turbid cells.

DART can work in 3 operating modes: flux tracking, Lidar and Monte Carlo. Only, the flux tracking mode is considered here. This mode tracks emitted and scattered radiation fluxes (i.e., watts) within angular cones. The Monte Carlo mode tracks individual photons that are emitted by the sun or a sensor. It is a reference tool for testing the accuracy of the flux tracking mode. The Lidar mode uses the Monte Carlo mode and keeps track of the path length (i.e., time) of each single photon.

For the flux tracking mode, there are 3 sub modes:

- Mode reflectance (R): sun is the only source of radiation. Atmosphere is a secondary source.

- Mode temperature (T): the atmosphere and the land surfaces are the sources of radiation. They depend on temperature and wavelength, using either the Planck's law or the Boltzmann law. Boltzmann law is especially useful for simulation radiation budget over the whole spectrum.

- $\quad$ Mode $(R+T)$ : the sun, atmosphere and land surfaces are the radiation sources. This mode is very useful for simulating remote sensing measurements in the $3-4 \mu \mathrm{m}$ spectral domain.

For the 3 modes, the atmosphere can be treated as a propagating medium or as an interface. In any case, landscape irradiance has 2 components: direct sun $\mathrm{W}\left(\Omega_{\mathrm{s}}, \mathrm{x}, \mathrm{y}\right)$ and atmospheric $\mathrm{W}_{\mathrm{a}}\left(\Omega_{\mathrm{n}}, \mathrm{x}, \mathrm{y}\right)$ source vectors. $\mathrm{W}\left(\Omega_{\mathrm{s}}\right)$ propagates along direction $\left(\Omega_{\mathrm{s}}\right) . \mathrm{W}\left(\Omega_{\mathrm{s}}\right)$ and $\mathrm{W}_{\mathrm{a}}\left(\Omega_{\mathrm{n}}\right)$ are simulated from a fictitious cell layer on top of the scene (Figure 1 ), with values equal to:

$$
\mathrm{W}\left(\Omega_{\mathrm{s}}\right)=\mathrm{E}_{\mathrm{s}}\left(\Omega_{\mathrm{s}}\right) \cdot\left|\mu_{\mathrm{s}}\right| . \Delta \mathrm{x} \cdot \Delta \mathrm{y} \quad \text { and } \quad \mathrm{W}_{\mathrm{a}}\left(\Omega_{\mathrm{n}}\right)=\mathrm{L}_{\mathrm{a}}\left(\Omega_{\mathrm{n}}\right) \cdot\left|\mu_{\mathrm{n}}\right| . \Delta \mathrm{x} \cdot \Delta \mathrm{y} \cdot \Delta \Omega_{\mathrm{n}}
$$

where $\Delta x . \Delta y$ is the area of the cell face, $\mu_{s}=\cos \theta_{s}, \mu_{n}=\cos \theta_{n}, E_{s}\left(\Omega_{s}\right)$ is the solar constant at the top of the scene, and $\Omega_{\mathrm{s}}$ denotes the solar incident direction. $\mathrm{L}_{\mathrm{a}}\left(\Omega_{\mathrm{n}}\right)$ is the atmospheric radiance along direction $\left(\Omega_{\mathrm{n}}\right)$, with $\mathrm{n} \in\left[\begin{array}{ll}1 & \mathrm{~N}^{\prime}\end{array}\right]$, where $\mathrm{N}^{\prime}$ is the number of downward discrete directions. It is null at the top of the atmosphere.

DART landscape modeling is as independent as possible from the RT modeling in order to allow DART to simulate RT on landscapes simulations that are generated by any other model. It can combine them with its own simulated landscapes. Imported landscapes and landscape elements can be edited to some extent. Geometric transformations (i.e., 3D translation, 3D homothety, 3D rotation) can be applied and optical properties can be assigned.

DART uses 2 complementary approaches for simulating landscapes:

- Juxtaposition of cells that contain one or several turbid medium (i.e., cloud of infinitely small planar elements). This is useful for simulating volumes of foliar elements such as grass and tree crown. A turbid medium is characterized by its volume density, an angular distribution and optical properties (i.e., abaxial reflectance, adaxial reflectance, transmittance). 
- Juxtaposition of translucent triangles. This is useful for simulating the ground, the branches, the urban surfaces (i.e., walls and roofs) and also foliar elements. A single cell can contain several turbid medium and several triangles or part of them.

In addition to the atmosphere and to the ground and its topography, DART simulates 4 types of landscape elements:

- Trees with exact or random locations and specific optical properties. Each tree is made of a trunk, possibly with branches, simulated as triangles, and a tree crown simulated as the juxtaposition of turbid cells. Tree crown can have a number of predefined shapes (e.g., ellipsoid, cone, trapezoid, etc.), with specific vertical and horizontal distributions of leaf volume density. Trees with different geometric and optical properties can be mixed.

- Grass or crops. They are simulated as a volume of turbid medium. This volume can located anywhere in space $(x, y, z)$.

- Urban elements (i.e., houses, roads,...). The basic element is a house with walls characterized by the location of their 4 upper corners and roofs characterized by their 4 upper corners.

- Water elements (i.e., river, lake). They are simulated as surfaces with any optical property (e.g., anisotropic reflectance possibly with specular component).

Generally speaking, two types of radiation interaction take place. (1) Volume interaction within turbid cells (Gastellu-Etchegorry et al., 2004). (2) Surface interaction on triangles (Gastellu-Etchegorry, 2008). First scattering order is exactly computed in turbid cells, using 2 points on the ray path within the cell: one point for upward scattering and one point for downward scattering. As expected, simplifying hypotheses are used for simulating multiple scattering in turbid cells. Its computation uses a much faster method than the initial "harmonic expansion" method: it uses the energy intercepted within a finite number of incident angular sectors $\Omega_{\text {sect, } \mathrm{k}}$ that sample the $4 \pi$ space of directions $\left(\Sigma \Omega_{\text {sect, } \mathrm{k}}=4 \pi\right)$. An angular sector $\Omega_{\text {sect }}$ is a set of close discrete directions. Their number can be as large as the number of directions of ray propagation, but a number equal to 6 leads to very accurate results, with relative errors smaller than $10^{-3}$ (Gastellu-Etchegorry et al., 2004). Actually, these points are computed for each sub-face of each cell face $f\left(f \in\left[\begin{array}{ll}1 & 6\end{array}\right]\right)$ that intercepts incident rays, and for each angular sector "incident" on the cell face (Martin, 2006; Grau, 2011). This implies that intercepted vector sources $W_{\text {int }}\left(\mathrm{s}, \mathrm{f}, \Omega_{\text {sect, } \mathrm{k}}\right)$ are stored per sub face $\mathrm{s}$ of cell face $\mathrm{f}$ and per incident angular sector $\Omega_{\text {sect,k. Thus, we have: }}$ $\mathrm{W}_{\text {int }}\left(\mathrm{s}, \mathrm{f}, \Omega_{\text {sect, } \mathrm{k}}\right)=\Sigma \Omega_{\mathrm{s}} \mathrm{W}_{\text {int }}\left(\mathrm{s}, \mathrm{f}, \Omega_{\mathrm{s}}\right)$, with directions $\left(\Omega_{\mathrm{s}}\right)$ within $\left(\Omega_{\text {sect, } \mathrm{k}}\right)$. For the case "direct sun illumination", there is 1 sector only.

Atmospheric R.T. modeling is implemented for any spectral band in the optical domain from the ultraviolet up to the thermal infrared (Gascon, 2001; Grau and Gastellu-Etchegorry, 2011). It simulates the atmospheric backscattering phenomenon, which avoids the need to couple DART with an atmospheric model. Atmospheric optical properties are characterized by the molecular $\mathrm{P}_{\mathrm{m}}\left(\lambda, \Omega^{\prime}, \Omega\right)$ and aerosol $\mathrm{P}_{\mathrm{p}}\left(\lambda, \Omega^{\prime}, \Omega\right)$ phase functions and by a number of profiles (molecular extinction coefficient $\alpha_{e}^{m}(\lambda, z)$ and spherical albedo $\omega_{\mathrm{m}}(\lambda, \mathrm{z})$, aerosol extinction coefficient $\alpha_{e}^{p}(\lambda, z)$ and spherical albedo $\left.\omega_{\mathrm{p}}(\lambda, \mathrm{z})\right)$. These quantities are specified by the operator or come from a data base $([0.3 \mu \mathrm{m} 30 \mu \mathrm{m}])$ pre-computed with the Modtran atmospheric model (Berk et al., 1989), for a few predefined atmospheres. DART TOA (Top Of the Atmosphere) reflectance, transmittance and brightness temperature values are very close to Modtran simulations for any atmosphere, any BOA (Bottom Of the Atmosphere) surface and sun / view configuration (Grau, 2011). 
Several tools are integrated in the DART model for facilitating the task of the users. Major tools are listed below:

- Sequencer of simulations: it runs a set of simulations where a predefined number of DART input variables vary. For example, one can run $\mathrm{A}_{1}{ }^{\mathrm{N} 1} \cdot \mathrm{A}_{2} \mathrm{~N}^{\mathrm{N}} \cdot \mathrm{A}_{3} \mathrm{~N} 3 \cdot \mathrm{A}_{4} \mathrm{~N} 4 \ldots$ simulations where DART input variables $A_{1}, A_{2}, A_{3}$.. take $N_{1}, N_{2}, N_{3}, \ldots$, values, respectively. Results are stored in a LUT (Look Up Table) for further display and / or processing.

- Manipulation of DEM (Digital Elevation Model): this is used for importing, creating and resampling DEMs.

- Simulation of foliar spectra with the Prospect model (Jacquemoud and Baret, 1990).

- Simulation of scene spectra (reflectance, brightness temperature, radiance). It can be computed using a single DART simulation that is conducted with $\mathrm{N}$ spectral bands, or with the help of the sequencer for running N DART simulations with 1 spectral band each.

- Simulation of broadband reflectance, brightness temperature, radiance, irradiance,... It is the sum of a few DART simulated narrow spectral bands, possibly weighted by sensor spectral sensitivity.

- Importation of land cover maps for a direct simulation of DART scenes.

DART models and tools are managed with a user friendly Graphic User Interface (GUI: Figure 2) to input all necessary parameters (e.g., view and illumination conditions) and to specify the required products. They can be also managed with command lines such as scripts written in Python programming language. DART computation code is written in $\mathrm{C}++$ language (more than 300000 lines of code). The GUI is written in Java language.

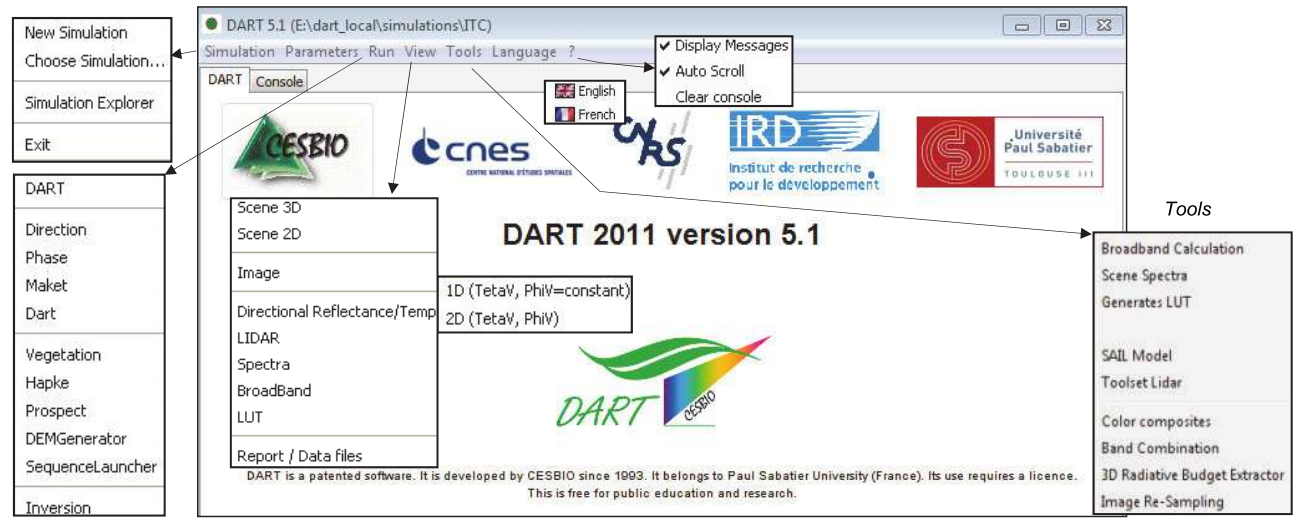

Fig. 2. Graphic User Interface of DART.

'Simulation': creation of simulation folders. 'Parameters': input of DART parameters. 'Run': simulation of scene and RT. 'View': display of results. 'Tools': for deriving products from DART simulations.

DART provides two major types of products:

- Remote sensing measurements at 3 altitude levels: BOA, TOA and atmosphere level. Measurements are essentially images for the "Flux tracking" mode and waveforms for the "Lidar" mode. Images are simulated in the focal plane of the satellite sensor. The cross section of the emitters and scatterers at the origin of the signal are taken into 
account for improving the image quality, especially for scenes with marked 3D architectures (urban elements, topography). A bi-linear interpolation method is used for projecting the horizontal upper grid of the scene onto an over sampled grid in the sensor plane, at any altitude (BOA to TOA).

- Radiative budget: 3D, 2D and 1D distribution of the radiation that is intercepted, scattered, emitted and absorbed.

\section{Examples of DART simulations}

DART potential for simulating remote sensing images of urban and forest canopies is illustrated here with 2 examples.

\subsection{Urban canopy}

The example shown here is derived from the CAPITOUL project of Meteo France (Masson et al., 2007) that took place over the city of Toulouse, France, from February 2004 to February 2005. Study of urban energy balance was one of the objectives. For that, different types of measurements took place: acquisition of TIR airborne images, in-situ measurements of turbulent fluxes, surface energy balance, surface temperatures, etc. DART was used for simulating remote sensing images and the radiative budget (GastelluEtchegorry, 2008). First, we developed a specific program for creating a DART scene from the urban database (Autocad format) and digital elevation model (DEM) of the Toulouse town hall (France). This led to the creation of DART objects (e.g., houses, trees). The fact that urban elements in the data base are not individual houses or buildings but unrelated walls and roofs was a difficulty. Figure 3 shows nadir (a) and oblique (b) color composites of the St Sernin district of Toulouse city. They were created with DART simulations in the blue, green and red spectral bands. Simulations stress that urban reflectance and brightness temperature values display a marked angular heterogeneity. This heterogeneity is illustrated here with the angular distribution of NIR reflectance values of St Sernin district (Figure 4).

Figure 3.c and d display DART remote sensing images of St Sernin basilica, in the center of district. They are simulated for a sensor at the bottom of the atmosphere (i.e., BOA image) and for a sensor at the top the atmosphere (TOA). The bluish tone of the TOA image, compared to the BOA image, is due to the fact that atmosphere scatters more in the blue than in the red spectral domain. DART images realism is very useful for verifying that the land surface is correctly simulated. Moreover, it helps also for testing the coherence of the RT. For example, at the $1^{\text {st }}$ scattering order, the reflectance of shadows is null.

\subsection{Forests}

One considers here DART simulations of the reflectance of a tropical forest (Sumatra, Indonesia) in the visible (VIS), near infrared (NIR) and short wave infrared (SWIR) spectral domains. Optical and geometric characteristics are given in Gastellu-Etchegorry et al., 1998. Sun direction is characterized by a $35^{\circ}$ off-nadir angle $\left(\theta_{\mathrm{s}}\right)$ and a $200^{\circ}$ azimuth angle $\left(\phi_{\mathrm{s}}\right)$. Figure 5 shows DART VIS images for three viewing directions: nadir viewing direction $\left(\theta_{\mathrm{v}}=0^{\circ}\right)$, sun backscattering viewing direction $\left(\theta_{\mathrm{v}}=35^{\circ}, \phi_{\mathrm{v}}=200^{\circ}\right)$, also called hot spot configuration, and specular configuration $\left(\theta_{\mathrm{v}}=35^{\circ}, \phi_{\mathrm{v}}=20^{\circ}\right)$. 


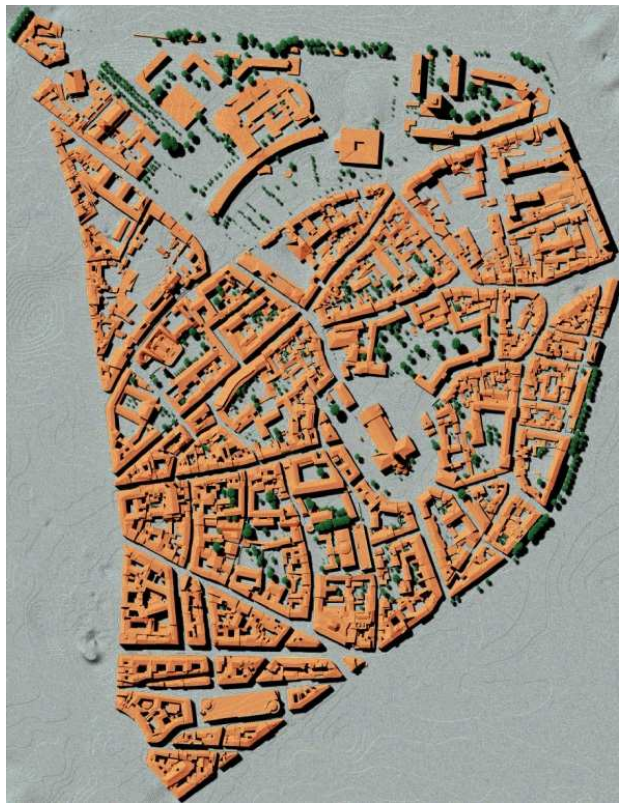

a)

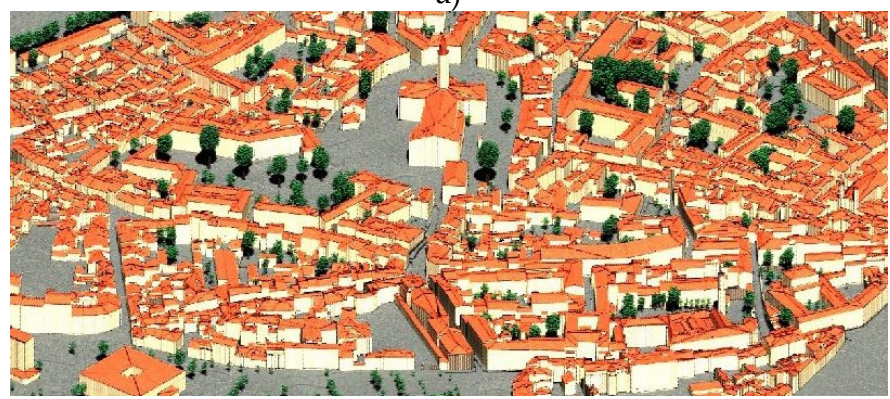

b)

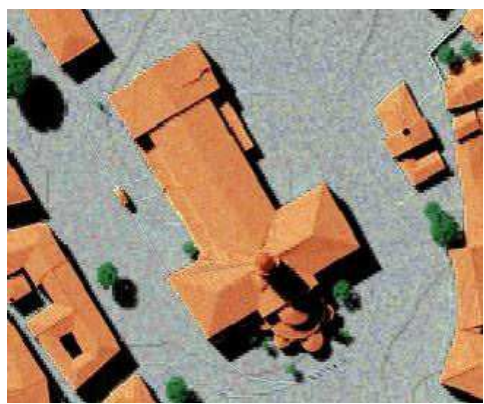

c)

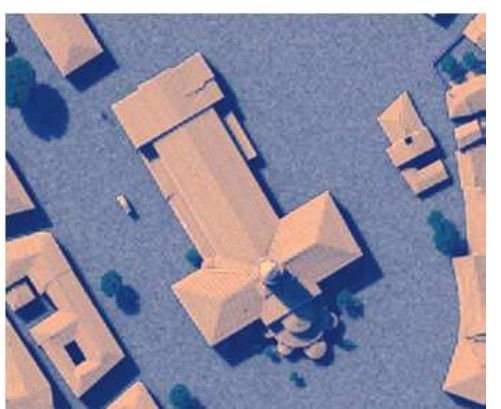

d)

Fig. 3. DART simulated nadir (a) and oblique (b) images of St Sernin district. They are color composites made with blue, green and red DART simulated images. c) Zoom of central part of a): St Sernin basilica. d) Top of the atmosphere simulation. 


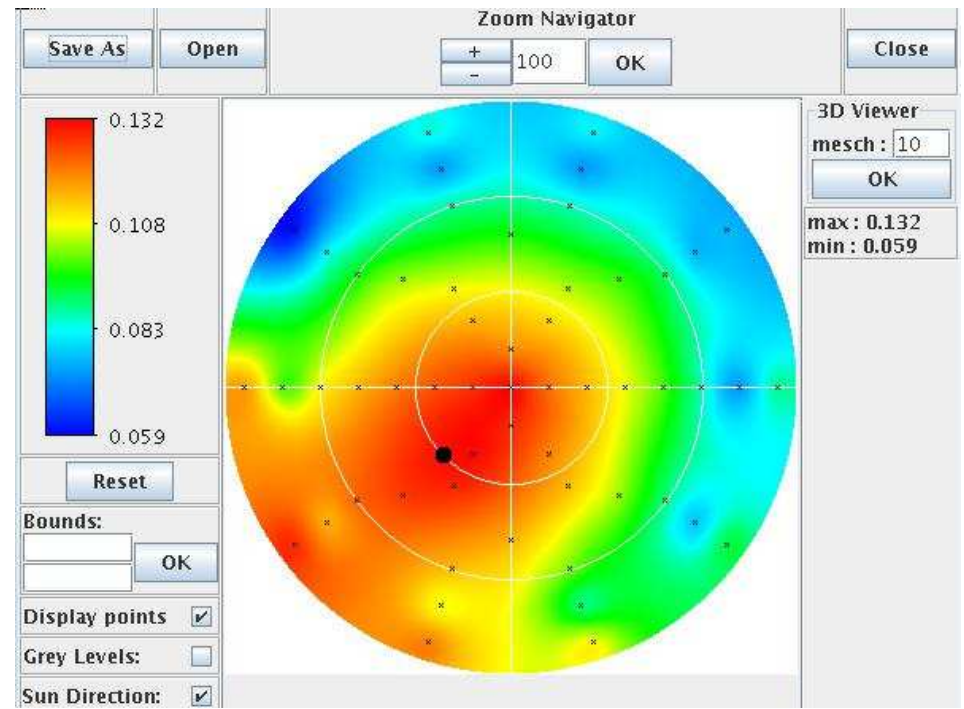

Fig. 4. Example of near infrared BRF of St Sernin district.

It is computed with simulated reflectance values (crosses), for a sun direction shown by a black circle. Distance from the circle centre gives the view zenith angle $\left(\left[090^{\circ}\right]\right)$ and the anti clockwise angle from the horizontal axis gives the azimuth view angle $\left(\left[0360^{\circ}\right]\right)$.
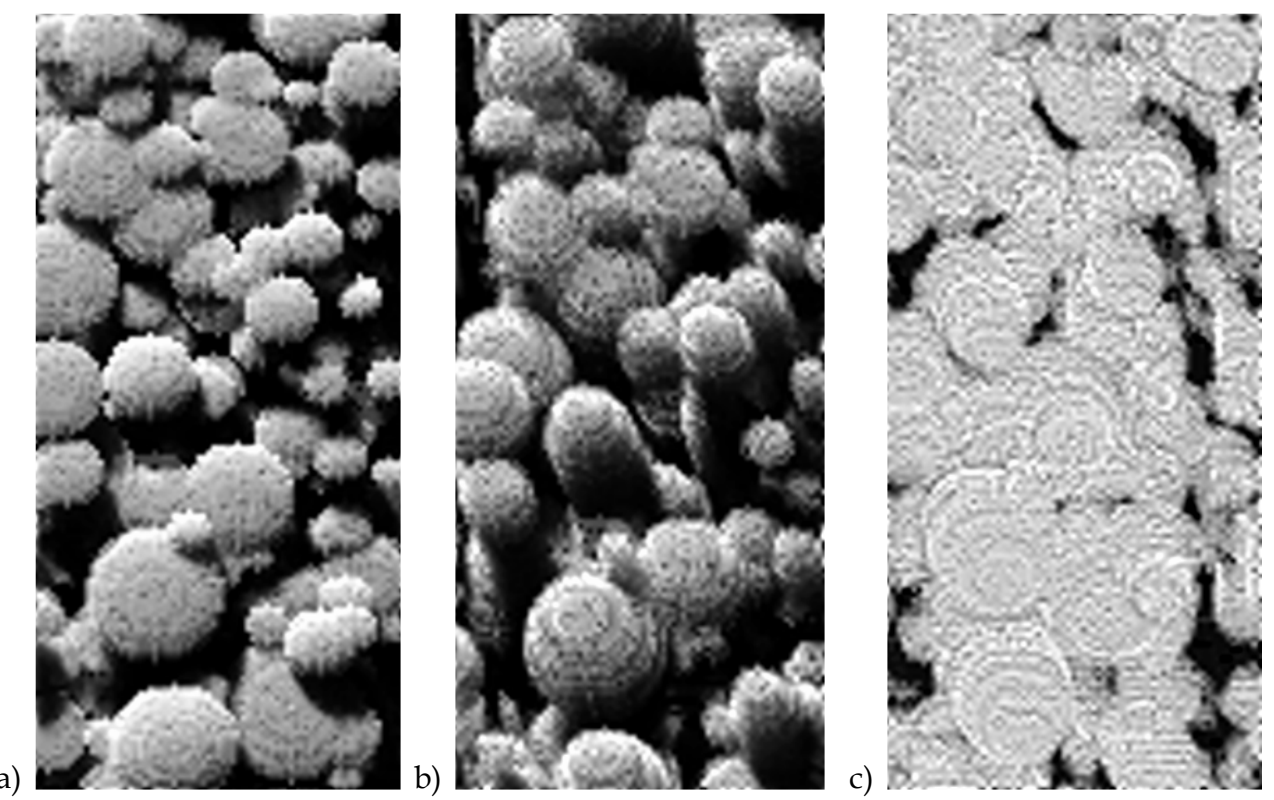

Fig. 5. VIS DART images of tropical forest (Sumatra, Indonesia). Sun direction: $\theta_{\mathrm{s}}=35^{\circ}$, $\phi_{\mathrm{s}}=200^{\circ}$. (a) Nadir $(\rho \approx 0.031)$, (b) specular $\left(\theta_{\mathrm{v}}=35^{\circ}, \phi_{\mathrm{v}}=20^{\circ}: \rho \approx 0.023\right)$, and (c) hot spot $(\rho \approx 0.091)$ viewing directions. SKYL $=0$. 
- Nadir viewing direction (Figure 5.a). Mean canopy reflectance is $\left(\rho_{\text {vis }} \approx 0.031, \rho_{\text {nir }} \approx 0.376\right.$, $\rho_{\text {swir }} \approx 0.143$ ). Illuminated and shaded tree crowns have very different reflectances, shown here with gray tones. Only trees of the upper canopy are easily distinguished. Surfaces with a reflectance smaller than 0.02 , i.e. shaded crowns and understory, represent $36 \%$ of the total scene area. Reflectance of illuminated crown is $\rho_{\mathrm{vis}} \approx 0.048$ $\left(\rho_{\text {nir }} \approx 0.55, \rho_{\text {swir }} \approx 0.21\right)$.

- Specular direction (Figure 5.b), i.e. $\left(\theta_{\mathrm{v}}=35^{\circ}, \phi_{\mathrm{v}}=20^{\circ}\right)$. Mean canopy reflectance is $\left(\rho_{\text {vis }} \approx 0.023, \rho_{\text {nir }} \approx 0.344, \rho_{\text {swir }} \approx 0.119\right)$. The reflectance difference between nadir and specular directions stresses the non lambertian nature of forest BRF. Vertical sides of tree crowns can be observed, which explains why trees appear with larger dimensions, compared to nadir viewing direction. This forward scattering configuration is mainly characterized by the important proportion of dark shadows, i.e. light trapping, due to the 3-D distribution of trees. Surfaces with a reflectance smaller than 0.02, i.e. shaded crowns and understory, occupy $50 \%$ of the total scene area. Reflectance of illuminated crown is ( $\rho_{\text {vis }} \approx 0.037, \rho_{\text {nir }} \approx 0.51, \rho_{\text {swir }} \approx 0.18$ ). Thus, crown VIS, NIR and SWIR reflectance is smaller than in the nadir configuration. This is explained by the fact the sunlit crown fraction and the leaf scattering phase function $\frac{1}{4 \pi} \cdot \mathrm{P}\left(\Omega_{\mathrm{s}}, \Omega_{\mathrm{v}}\right)$ are smaller.

- hot spot configuration (Figure 5.c), i.e. $\left(\theta_{\mathrm{v}}=35^{\circ}, \phi_{\mathrm{v}}=200^{\circ}\right)$. The absence of shade in this configuration explains the strong canopy reflectance in all spectral domains, i.e. $\rho_{\text {vis }} \approx 0.091 \quad\left(\rho_{\text {nir }} \approx 0.684, \rho_{\text {swir }} \approx 0.341\right)$. Darkest areas correspond to the low reflecting understory. Their reflectance is less than 0.03 and occupy about $5 \%$ of the total scene area. Crown reflectance is $\left(\rho_{\mathrm{vis}} \approx 0.1, \rho_{\mathrm{nir}} \approx 0.74, \rho_{\mathrm{swir}} \approx 0.4\right)$.

Figure 6 shows DART NDVI (Normalized Vegetation Index) and VIS / NIR / SWIR reflectance values in the principal and perpendicular solar planes, for several sun off-nadir directions. Reflectance values share some similar characteristics: (1) a well marked bowl shape in the principal solar plane with a spectrally dependent minimum for a direction between the specular and nadir directions, (2) a strong maximum in the hot spot direction, more marked in the VIS than in the NIR and SWIR, (3) a systematic increase of reflectance if view zenith angles exceed a threshold value (e.g. $\approx 50^{\circ}$ in the VIS if $\left.\theta_{\mathrm{s}}=0^{\circ}\right)$, which depends on the spectral domain and the sun direction, (4) an azimuth symmetry relative to the principal solar plane, and (5) a relatively small variability in the perpendicular solar plane.

Reflectance is maximal at hot spot $\left(\rho_{\mathrm{vis}}=0.073, \rho_{\text {nir }}=0.615, \rho_{\mathrm{swir}}=0.324\right)$ and minimal for directions between nadir and specular configurations $\left(\rho_{\mathrm{vis}}=0.025, \rho_{\mathrm{nir}}=0.354, \rho_{\mathrm{swir}}=0.12\right.$ ), whereas NDVI is minimal $(\approx 0.79)$ in the hot spot direction and maximal $(\approx 0.87)$ in the specular direction.

In addition to DART simulations, Figure 6 shows reflectance simulations carried out with the well known SAIL model (Verhoef, 1984). For this model, vegetation is an homogeneous turbid medium. Figure 6 allows one to stress the role of canopy architecture on forest reflectance. Its neglect by the SAIL model explains that DART reflectance is much smaller. Reflectance differences depend a lot on view direction. Smaller differences occur in the hot spot directions because no shadows occur for these viewing directions. Outside the hot spot configuration, for $\theta_{\mathrm{s}}=0^{\circ}$, mean relative reflectance difference is around $60-70 \%$ in the VIS, $50 \%$ in the SWIR and 25\% in the NIR. Differences tend to increase with sun off-nadir angle.

The bowl shape of VIS and SWIR reflectance is more marked with SAIL than with DART. It corresponds to the fact that in the forward principal plane, for large off-nadir viewing angles $\theta_{\mathrm{v}}$, an increase of $\theta_{\mathrm{v}}$ implies that DART reflectance increases less than SAIL 
reflectance, especially for large off-nadir sun angles. Indeed, the canopy 3-D heterogeneous structure ensures that an increase of $\theta_{\mathrm{v}}$ leads to an increase of the proportion of shaded tree crowns that are viewed in the principal plane. This effect tends to be less marked in the NIR than in the VIS because the role of shadows is less marked in the NIR, due to the increased occurrence of multiple scattering processes. Moreover, the presence of shadows explains that with oblique sun illumination, minimal values of DART reflectance are more shifted towards the specular direction than those of SAIL. This is also true for NDVI.

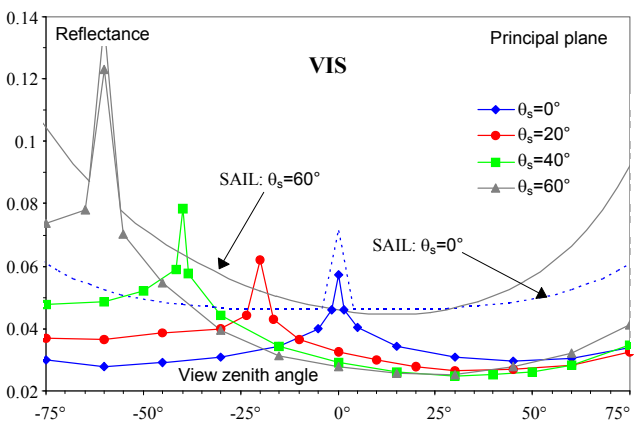

a)

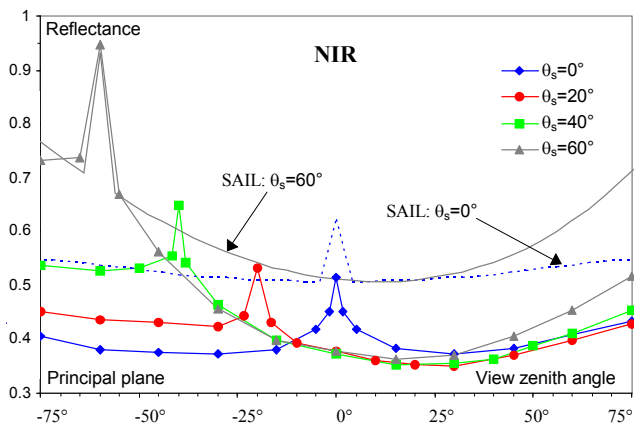

c)

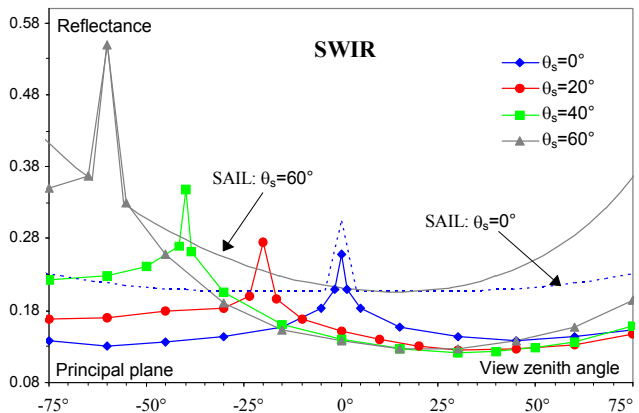

e)

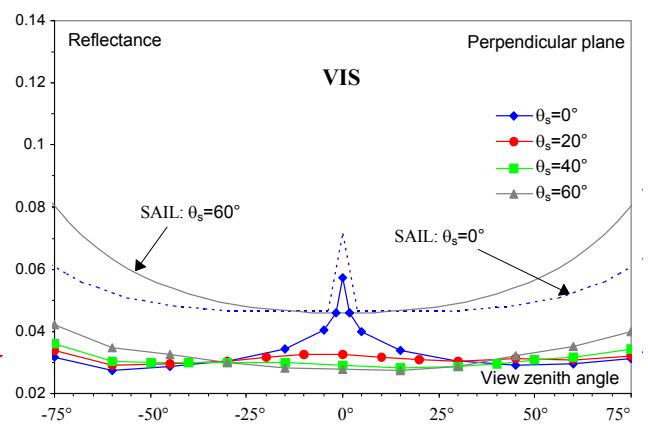

b)

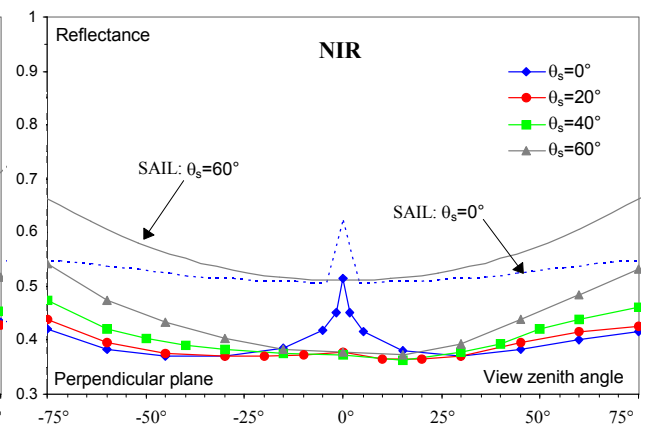

d)

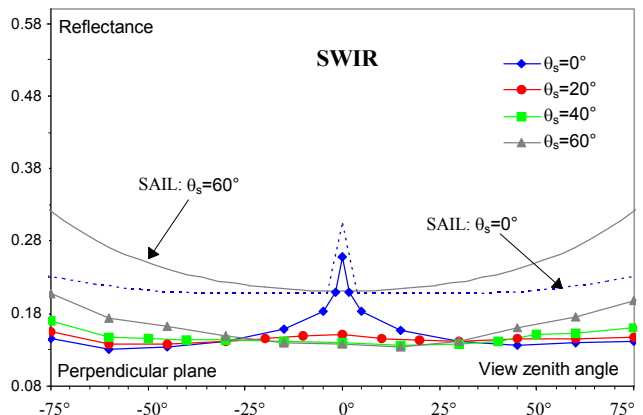

f) 


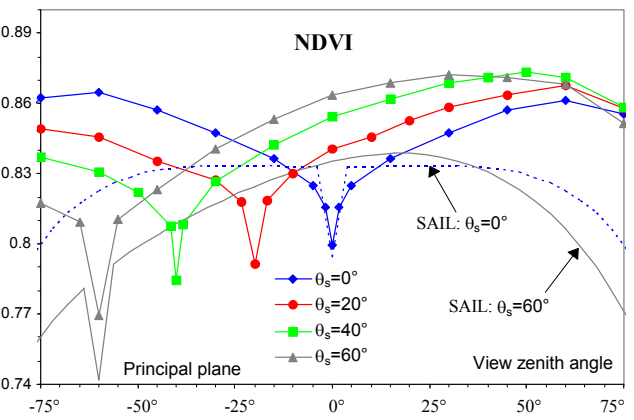

g)

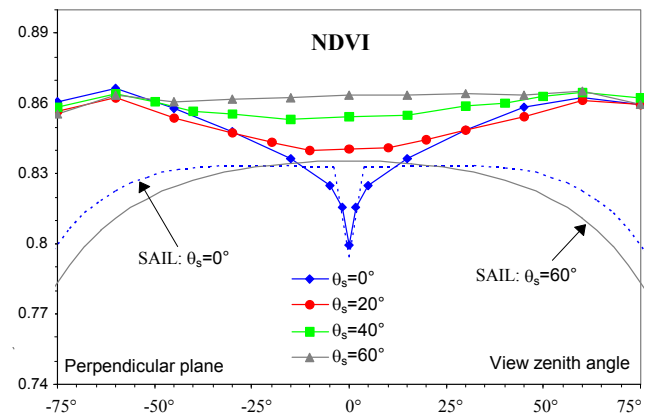

h)

Fig. 6. Tropical forest angular DART and SAIL VIS (a, b), NIR (c, d), SWIR (e, f) simulated reflectance and NDVI $(\mathrm{g}, \mathrm{h})$ for 4 sun off-nadir directions $\left(0^{\circ}, 20^{\circ}, 40^{\circ}, 60^{\circ}\right)$. Principal (left column) and perpendicular (right column) solar planes. SKYL is 0.3 for VIS, 0.24 for NIR and 0.09 for SWIR. For a better clarity SAIL simulations are for $\theta_{\mathrm{s}}=0^{\circ}$ and $60^{\circ}$ only.

Image simulation is very useful for understanding forest reflectance behavior with experimental and instrumental parameters. Here, this is shown for sky radiation. Figure 7 shows DART nadir NIR images of part of the tropical forest, for 2 extreme atmosphere conditions: SKYL equal to 0 and 1, with $S K Y L=\frac{\text { Atmosphere irradiance }}{\text { Totalirradiance }}$. We note that some tree crowns are invisible with SKYL=0 (bottom of Figure 7), because they are shaded, and

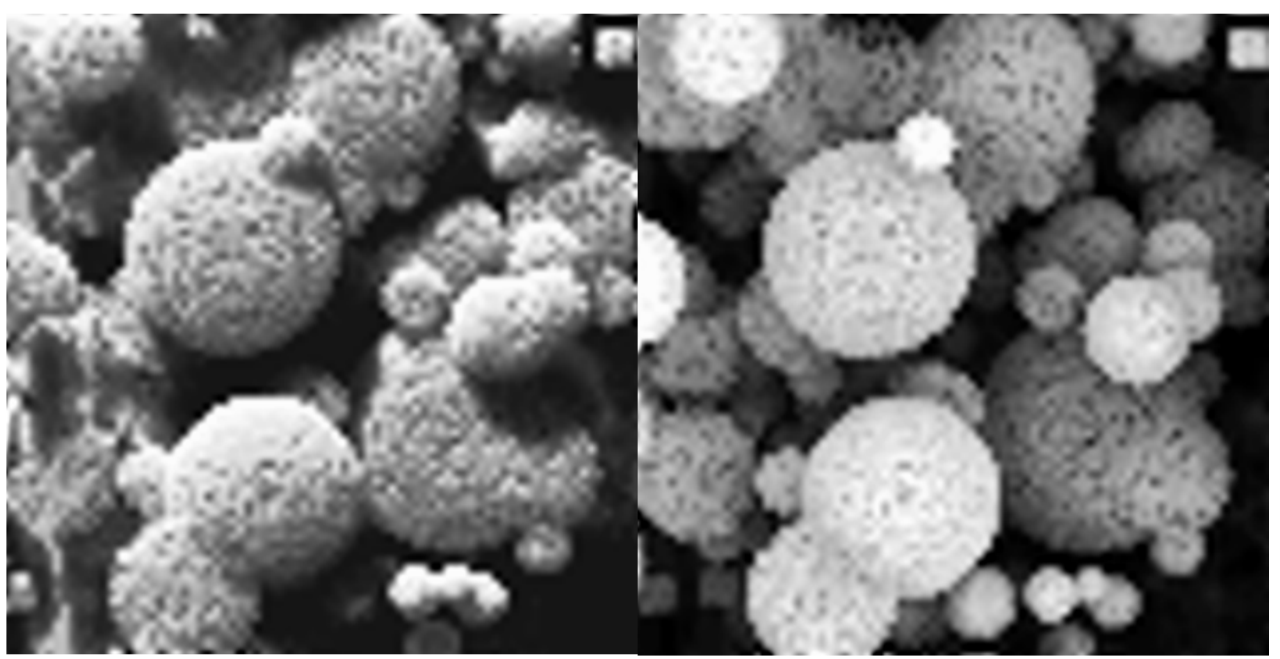

a) b)

Fig. 7. NIR DART nadir images of a tropical forest with SKYL equal to 0 (a) and 1 (b). Most crowns of upper trees that are shaded with $S K Y L=0$ are well lit if $S K Y L=1$. Moreover, shaded crowns of a few lower trees that are not viewed with SKYL $=0$ become visible if $\mathrm{SKYL}=1$. Sun off-nadir angle is $35^{\circ}$. 
visible with $S K Y L=1$. It explains that forest reflectance varies with atmosphere radiation. In a first approximation, we can consider that forest reflectance depends on the fraction of illuminated crowns, shaded crowns of upper trees, and shaded lower trees and understory (i.e. vegetation smaller than $10 \mathrm{~m}$ height). With $S K Y L=0(S K Y L=1)$, fractions of these 3 classes are around $48 \%(68 \%), 37 \%(12 \%)$ and $15 \%(20 \%)$, respectively, whereas their apparent NIR reflectances are around $0.55(0.52), 0.27(0.14)$ and $0.069(0.062)$, respectively. As expected, a SKYL increase implies that the area of illuminated crowns increases whereas their apparent reflectance slightly decreases. Indeed, with $S K Y L=1$ all upper trees are totally illuminated, conversely to the case SKYL=0. On the other hand, a SKYL increase implies that the fraction and reflectance of shaded upper trees regularly decrease, whereas the area and apparent reflectance of the shaded lower trees and understory remain nearly constant if SKYL $<0.5$. The fraction and reflectance decrease of the shaded upper tree crowns results from two opposite effects: when SKYL increases some crown surfaces, only slightly shaded if SKYL=0, become darker whereas crown surfaces that are initially totally shaded become better lit. Thus, when SKYL increases, tree crowns that are initially shaded with SKYL=0, can become lit enough to belong to the category "illuminated upper trees".

\section{Recent and on going improvements}

Three recent improvements of DART are briefly described here:

- $\quad$ Earth / Atmosphere curvature. It is important when simulating satellite measurements, because the usual assumption that the Earth is a flat surface is less and less valid with more and more oblique ray directions.

- Transformation of 3D objects made of juxtaposed triangles into 3D turbid objects.

- Finite landscapes and infinite landscapes with a continuous (i.e., not repetitive) topography.

- Simulation of Lidar waveform.

\subsection{Earth / Atmosphere curvature}

The Earth / Atmosphere curvature has an impact at 2 levels: (1) the incidence angle of sun and view directions of Earth surfaces, and (2) ray path lengths in the atmosphere. Both effects are now taken into account by DART.

View and sun incidence angle:

For a non-horizontal atmosphere, the incidence angle $\alpha$ differs from the satellite sensor off nadir angle $\beta$. DART computes $\alpha, \beta$ and the azimuth view direction in the Earth surface reference system with the locations (latitude, longitude, altitude) of the Earth target $\mathrm{T}$ and satellite sensor S, assuming the Earth to be an ellipsoid (cf. Annex).

Sun incidence angle at target level and on an horizontal surface below the satellite are computed by DART as a function of time with the equations of the NOAA solar calculator (http://www.esrl.noaa.gov/gmd/grad/solcalc/).

Ray paths in the atmosphere:

For an off-nadir angle $\theta$, an atmosphere path length between altitudes $z_{a}$ and $z_{b}$ is smaller than in an horizontal atmosphere (i.e., $\Delta \mathrm{z} /|\mu|$, with $\mu=\cos \theta$ and $\Delta \mathrm{z}=\left|\mathrm{z}_{\mathrm{a}}-\mathrm{z}_{\mathrm{b}}\right|$ ). Moreover, gas and aerosol vertical distributions are not constant. Here, atmosphere is assumed to be spherical (Figure 27). 


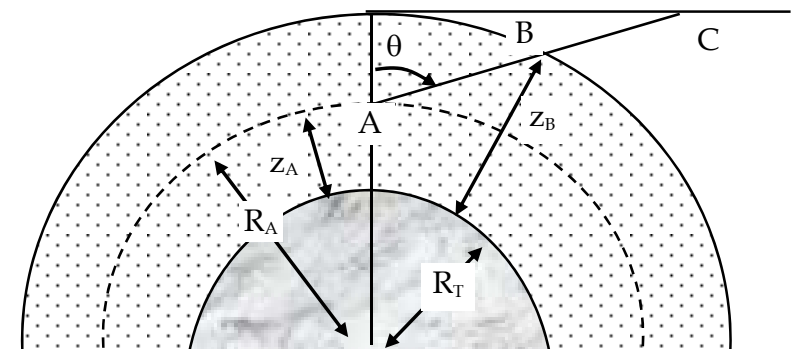

$\mathrm{R}_{\mathrm{T}}$ : Earth radius,

$R(z)$ : radius of the sphere at the altitude $z \cdot R(z)=R_{T}+z$

$\theta$ : zenith angle of a direction $(\mu=\cos \theta)$

Fig. 8. The atmosphere with the Earth curvature.

$$
\mu=\cos \theta>0 \text { : Path }\{\Delta z>0 ; \mu\} \text { is } A B=-R_{A} \cdot \mu+\sqrt{R_{A}^{2} \cdot \mu^{2}+\Delta z \cdot\left(\Delta z+2 R_{A}\right)}
$$

It can be viewed as a path $\left\{\Delta \mathrm{z} ; \mu_{\mathrm{sph}}\right\}$ in an horizontal atmosphere if:

$$
\mu_{s p h}=\frac{\Delta z}{-R_{A} \cdot \mu+\sqrt{R_{A}^{2} \cdot \mu^{2}+\Delta z \cdot\left(\Delta z+2 R_{A}\right)}} \Rightarrow A B=\frac{\Delta z}{\mu_{s p h}}<\frac{\Delta z}{\mu}
$$

$\mu=\cos \theta<0$ : Path $\{\Delta z<0 ; \mu\}$ is $A B=-R_{A} \cdot \mu-\sqrt{R_{A}^{2} \cdot \mu^{2}+\Delta z \cdot\left(\Delta z-2 R_{A}\right)}$

It can be viewed as a path $\left\{\Delta \mathrm{z} ; \mu_{\mathrm{sph}}\right\}$ in an horizontal atmosphere if:

$$
\mu_{s p h}=\frac{\Delta z}{R_{A} \cdot \mu+\sqrt{R_{A}^{2} \cdot \mu^{2}+\Delta z \cdot\left(\Delta z-2 R_{A}\right)}} \Rightarrow A B=\frac{-\Delta z}{\mu_{s p h}}<\frac{-\Delta z}{\mu}
$$

Note: the 2 expressions of $\mathrm{AB}$ and $\mu_{\mathrm{sph}}$ are identical. Indeed: $\{\mu>0, \Delta \mathrm{z}>0\}$ for the $1^{\text {st }}$ one and $\{\mu<0, \Delta z<0\}$ for the $2^{\text {nd }}$ one.

The optical depth of path $\mathrm{AB}$ is:

$\Delta \tau\left(z_{A}, \Delta z, \mu\right)=\int_{0}^{\Delta l=A B} \alpha(t) \cdot d l=\int_{z_{A}}^{z_{B}} \alpha(t) \cdot \frac{R_{A}+t}{\sqrt{R_{A}^{2} \cdot \mu^{2}+\mathrm{t} .\left(\mathrm{t}+2 R_{A}\right)}} \cdot d t$, with $\mathrm{t}$ the altitude relative to $\mathrm{z}_{\mathrm{a}}$

and 1 the path length from A, we have: $l=-R_{A}^{2} \cdot \mu+\sqrt{R_{A}^{2} \cdot \mu^{2}+\mathrm{t} \cdot\left(\mathrm{t}+2 R_{A}\right)} 1$ if $\mu>0$ and: $l=-R_{A}^{2} \cdot \mu-\sqrt{R_{A}^{2} \cdot \mu^{2}+\mathrm{t} .\left(\mathrm{t}-2 R_{A}\right)}$ if $\mu<0$.

The computation of $\Delta \tau\left(\mathrm{z}_{\mathrm{a}}, \Delta \mathrm{z}, \mu\right)$ could be solved with an integration by parts:

$$
\begin{aligned}
& \int_{Z_{A}}^{Z_{A}+\Delta z} \alpha(t) \cdot \frac{R_{A}+t}{\sqrt{R_{A}^{2} \cdot \mu^{2}+\mathrm{t} \cdot\left(\mathrm{t}+2 R_{A}\right)}} \cdot d t \\
& =\left[\alpha(t) \cdot\left(R_{A} \mu+\sqrt{R_{A}^{2} \cdot \mu^{2}+\mathrm{t} \cdot\left(\mathrm{t}+2 R_{A}\right)}\right]_{Z_{A}}^{Z_{A}+\Delta z}-\int_{Z_{A}}^{Z_{A}+\Delta z} \alpha^{\prime}(t) \cdot\left(-R_{A} \cdot \mu+\sqrt{R_{A}^{2} \cdot \mu^{2}+\mathrm{t} \cdot\left(\mathrm{t}+2 R_{A}\right)}\right) \cdot d t\right.
\end{aligned}
$$


This approach requires the derivative $\alpha^{\prime}(z)$ of the extinction coefficient. However, $\alpha^{\prime}(z)$ is known only for an ideal case such as an exponential atmosphere. In order to work with any atmosphere (e.g., non exponential vertical profile of $\left.\mathrm{O}_{3}\right), \Delta \tau\left(\mathrm{z}_{\mathrm{a}}, \Delta \mathrm{z}, \mu\right)$ is computed with: $\Delta \tau\left(z_{A}, \Delta z, \mu\right)=\overline{\alpha(z)} . A B=\overline{\alpha(z)} \cdot\left|\frac{\Delta z}{\mu_{s p h}}\right|$, with $\overline{\alpha(z)}$ the mean extinction coefficient within $\left[\mathrm{z}_{\mathrm{a}}\right.$ $\left.\mathrm{z}_{\mathrm{a}}+\Delta \mathrm{z}\right]$

Thus, before simulating the atmosphere RT, DART computes $\mu_{\mathrm{sph}}\left(\mathrm{Z}_{\mathrm{i}}, \mu_{\mathrm{j}}\right)$ for all I atmosphere layers and all $\mathrm{J}$ discrete directions, including the sun direction, with $\mathrm{i} \in\left[\begin{array}{ll}1 & \mathrm{I}\end{array}\right]$ and $\mathrm{j} \in[\mathrm{l} \mathrm{J}]$.

$$
\left|\mu_{s p h}\left(z_{i}, \mu_{j}\right)\right|=\frac{\Delta z}{-\left(R_{T}+z_{i}\right)^{2} \cdot\left|\mu_{j}\right|+\sqrt{\left(R_{T}+Z_{i}\right)^{2} \cdot \mu_{j}^{2}+|\Delta z| \cdot\left(|\Delta z|+2 \cdot\left(R_{T}+Z_{i}\right)\right)}}
$$

The use of $\mu_{\text {sph }}\left(\mathrm{z}_{\mathrm{i}}, \mu_{\mathrm{j}}\right)$ allows one to treat the atmosphere as an horizontal plane for simulating the atmosphere RT: any path $\delta \mathrm{r}\left(\mathrm{z}_{\mathrm{i}}, \mu_{\mathrm{j}}\right)$ that is computed for an horizontal atmosphere layer $\left[\mathrm{z}_{\mathrm{i}} \mathrm{z}_{\mathrm{i}}+\mathrm{Dz}\right]$ is replaced by $\delta r_{s p h}\left(z_{i}, \mu_{j}\right)=\delta r\left(z_{i}, \mu_{j}\right) \cdot \frac{\mu_{j} \cdot\left(z_{i}, \mu_{j}\right)}{\mu_{s p h} \cdot\left(z_{i}, \mu_{j}\right)}$.

We have: $\delta r_{s p h}\left(z_{i}, \mu_{j}\right) \leq \delta r_{s p h}\left(z_{i}, \mu_{j}\right) \leq \frac{\Delta z}{\mu_{j}}$

\subsection{Transformation of "3D triangle objects" into "3D turbid objects"}

As already mentioned DART can import 3D objects (Figure 9) that are simulated as groups of triangles. In many cases, especially for vegetation, these objects are simulated with tremendous numbers of triangles (e.g., $10^{6}$ triangles). This is very costly is terms of computation time and volume memory, especially if we work with forests... In order to solve this problem, we designed a module that transforms 3D objects simulated as triangles (i.e., 3D triangle objects) into 3D objects simulated as turbid medium (i.e., 3D turbid objects). Figure 10 shows the schematic approach. It is reminded that a cell filled with turbid medium is characterized by its LAI (Leaf Area Index), its leaf angle distribution (LAD) and the leaf optical properties (e.g., transmittance and adaxial and abaxial reflectance, possibly with specular parameters). The "transformation" module computes the LAI and LAD of all leaf

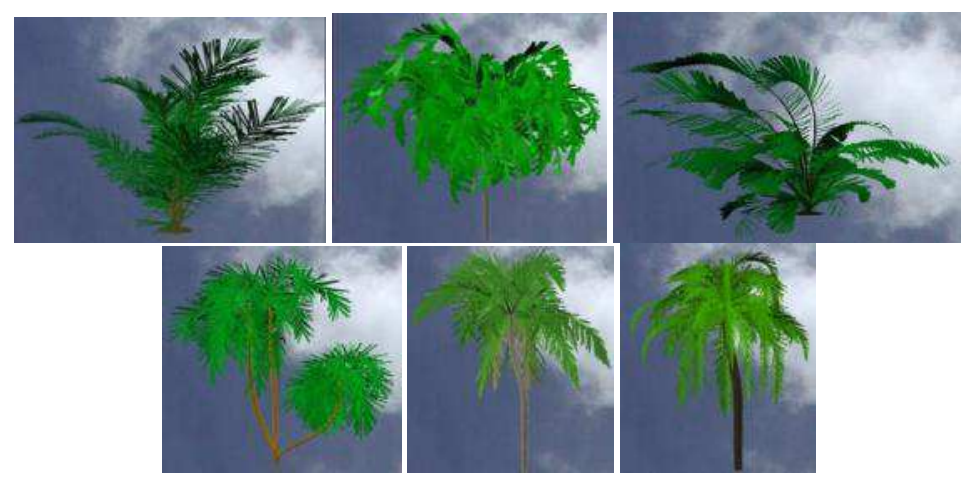

Fig. 9. Examples of 3D trees that are imported by DART. 
elements within each cell of a 3D cell matrix. This is done for all or part of the groups of triangles of the "3D triangle" object. Optical properties of the turbid medium are those of the triangles. On the other hand, the LAD is either the one that is computed or a predefined LAD. The possibility to use a predefined LAD is well adapted to the case of $3 \mathrm{D}$ triangle objects with low volume densities of triangles.
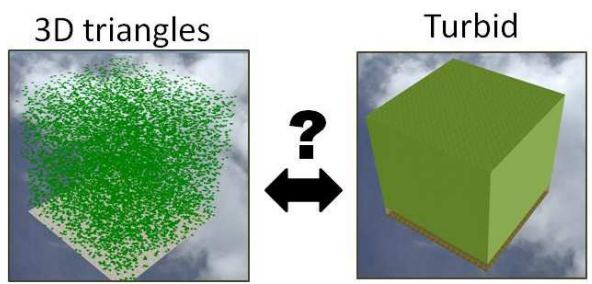

Fig. 10. Schematic representation of the transformation of a "triangle cell" into a "turbid cell".

Here, the transformation of a 3D triangle scene into a turbid 3D turbid scene is illustrated by DART color composite images of the citrus tree "3D triangle scene" and "3D turbid scene" (Figure 11). The associated 2D reflectance polar plots are shown also. For these 2 cases, RT was simulated in the blue, green and red spectral bands. Results are very encouraging: reflectance values are very close. Actually, reflectance values of the 3D triangle and turbid scenes are much closer than the 3D triangle objects contain a lot of triangles. It can be noted that DART images in Figure $11 \mathrm{~b}$ and e are duplicated $2 \times 2$ times. This mode of representation of images is often useful for better interpreting simulated images where objects (e.g., trees) and their shadows cross the scene boundaries. Compared to the usual simulation of trees with classical tree crown shapes such ellipsoids or cones, the transformation of 3D triangle tree crowns into 3D turbid tree crowns is very interesting for keeping the 3D architecture of trees.

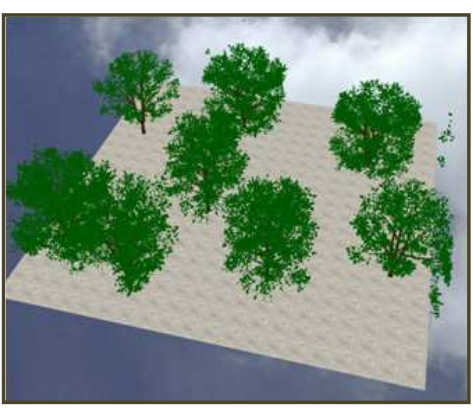

a)

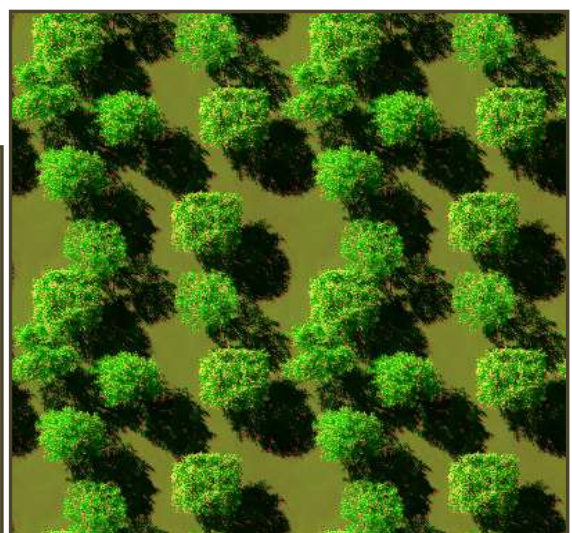

b)

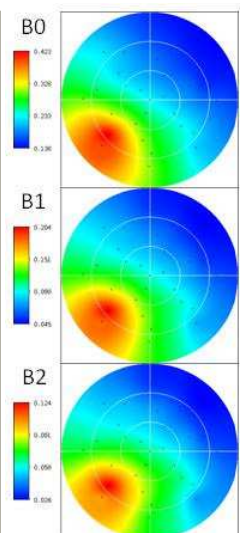

c) 


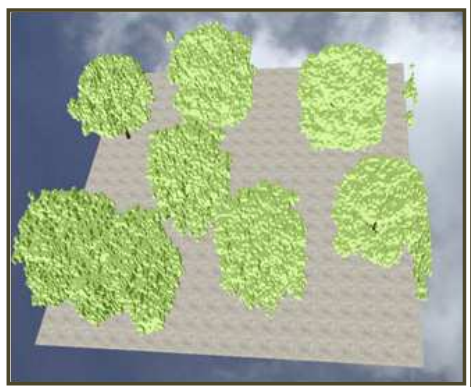

d)

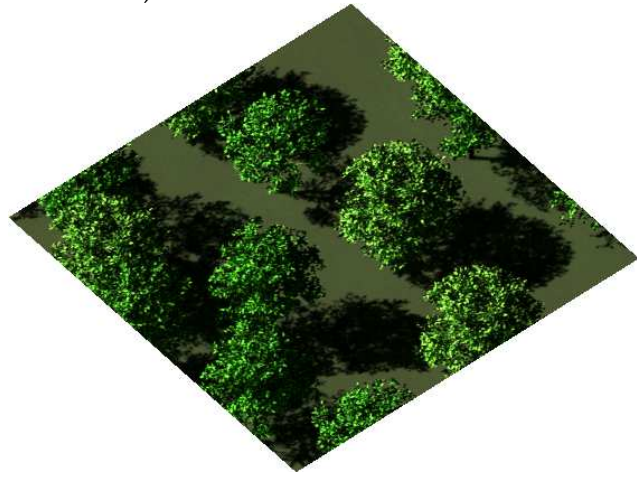

g)

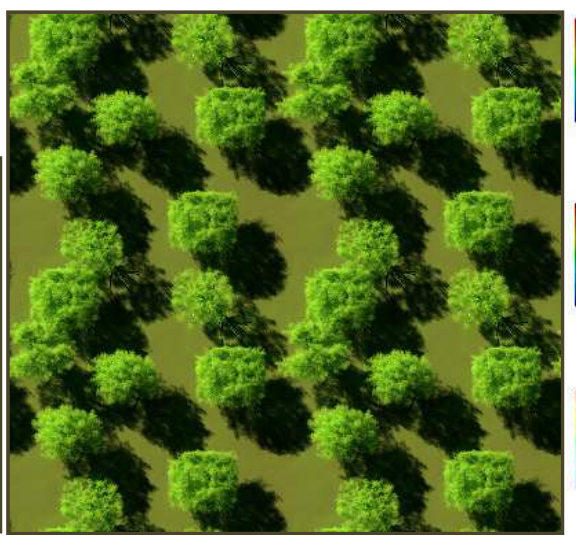

e)

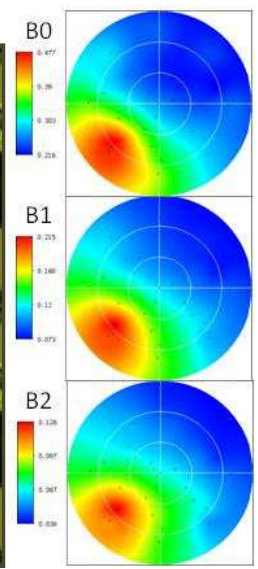

f)

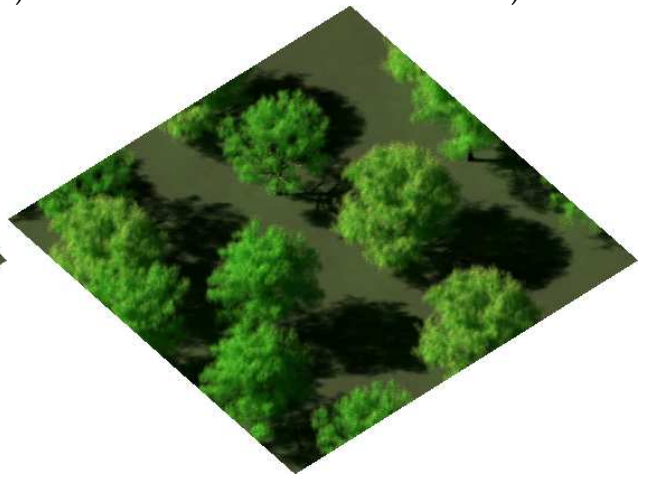

h)

Fig. 11. 3D triangle and turbid simulations in the blue (B0), green (B1) and red (B2) spectral bands of the citrus plot. a) 3D triangle scene. d) Derived 3D turbid scene. Associated triangle and turbid nadir $(\mathrm{b}, \mathrm{e})$ and oblique $(\mathrm{g}, \mathrm{h})$ color composite of the DART simulated images. $\mathrm{c}$, f) Associated 2D reflectance polar plots.

\subsection{Finite landscapes and continuous infinite landscapes topography}

DART was designed to operate with infinite scenes that are made of a DART simulated pattern that is periodic. When a ray exits the scene, it re-enters the scene by the scene opposite side. This is the so-called "repetitive topography" method. This approach is used in most 3D models. It works very well with landscapes without topography or if the topography is identical on the landscape opposite sides. Thus, it is erroneous in presence of any topography. It is also erroneous if one wants to simulate a finite landscape without interaction with their neighborhood. We solved these 2 problems by introducing 2 new landscape modeling methods, called "Continuous topography" and "Isolated landscape", respectively. This implied to adapt the 3 DART RT modeling modes (i.e., flux tracing, Monte Carlo and lidar). In short, landscapes can be simulated with 3 methods (Figure 12): 
- Repetitive topography: the landscape and the topography are periodic. It that case, a landscape with a simple slope is actually simulated as a series of periodic slopes, which implies undesirable illumination (Figure 12.a) and view (Figure 12.b) effects.

- Continuous topography: repetitive landscape with a continuous topography. It allows one to simulate more realistic landscapes such as infinite slopes. This method is well adapted to landscapes such as mountain slopes.

- Isolated landscape: no influence of the neighborhood.
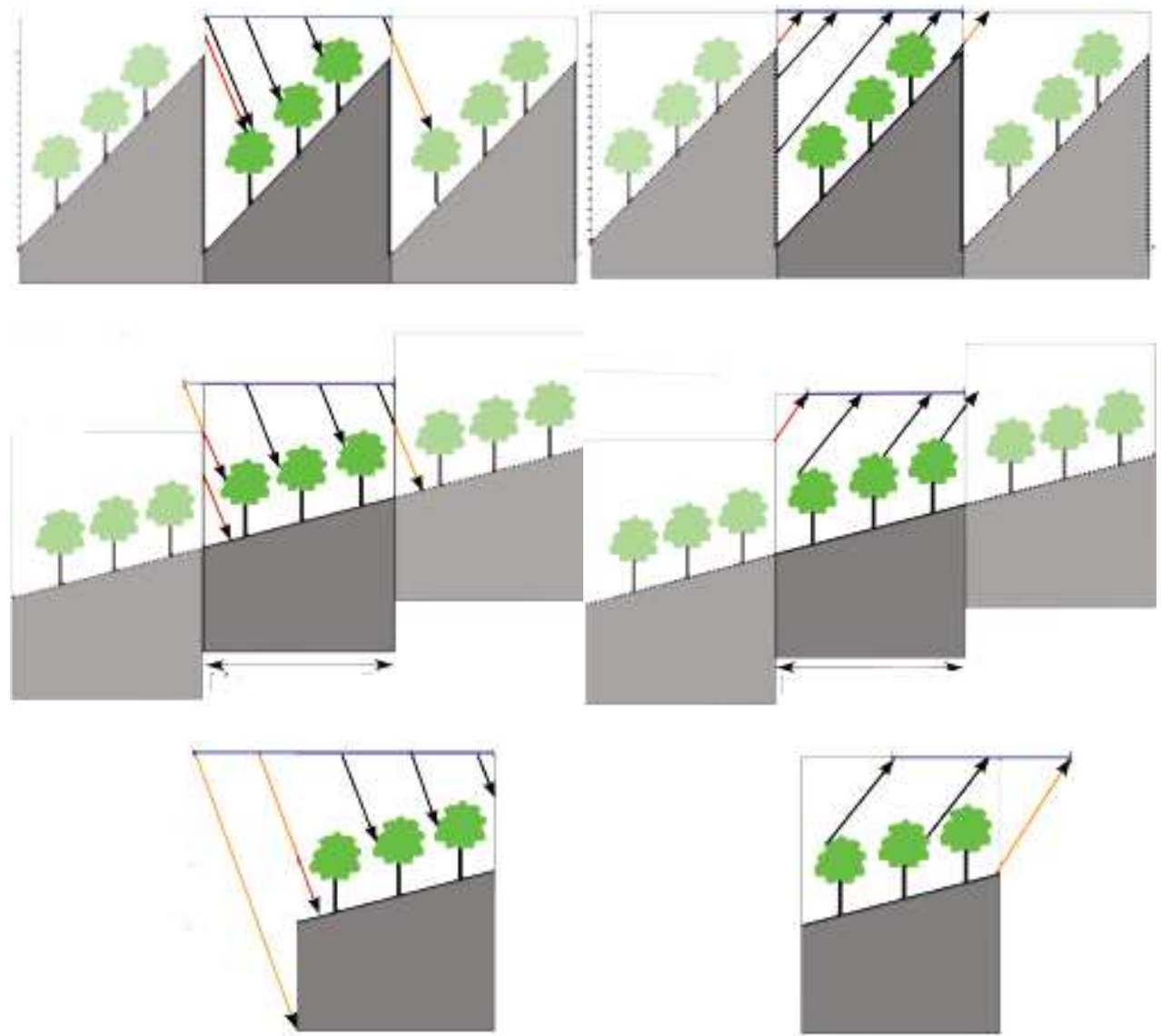

Fig. 12. The 3 methods of landscape simulation in DART. Top: Repetitive landscape. Middle: Continuous topography. Bottom: Isolated landscape. Left and right columns illustrate the illumination and view configurations.

Figure 13 illustrates the 3 methods for simulating landscapes. In the image simulated with the repetitive method, shadow is not continuous on the scene edges, due to the discontinuity of the slope. It would have been continuous in the absence of topography. On the other hand, as expected, shadow is continuous with the "Continuous method". As expected, for the "Isolated landscape", shadow is not continuous (no adjacency effects). 


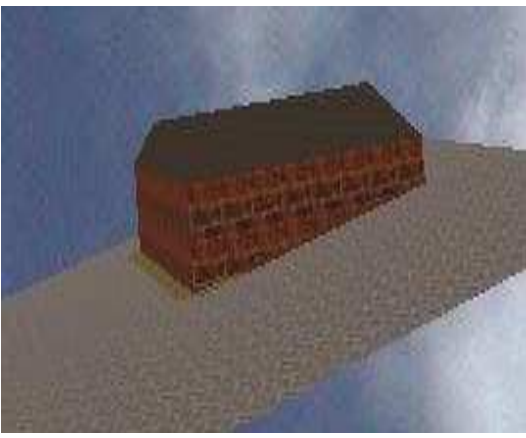

a)

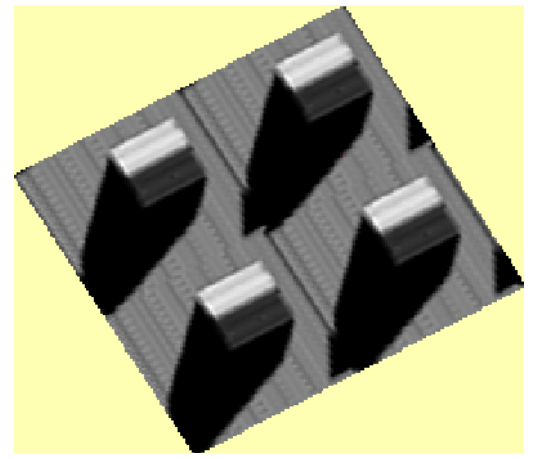

c)

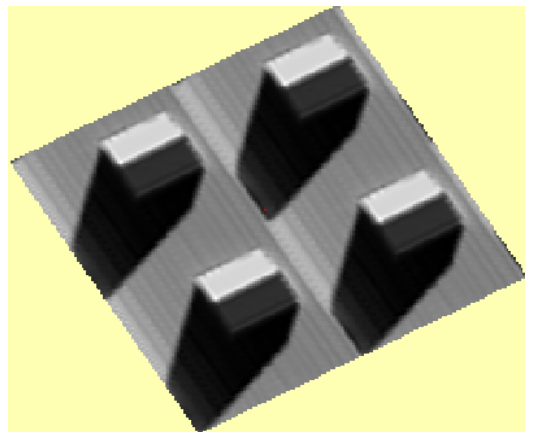

b)

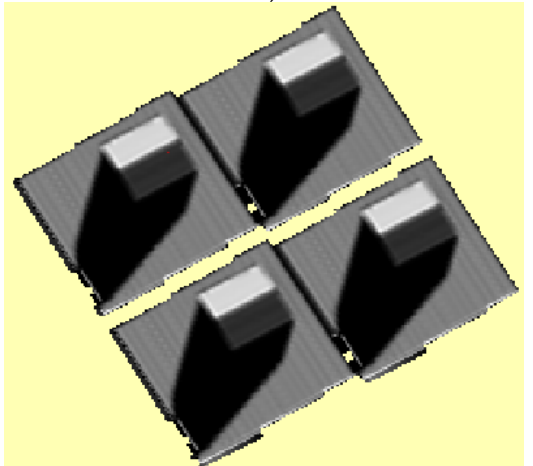

d)

Fig. 13. Simulation of a house on a slope.

a) Scene. b) Repetitive topography. c) Infinite (i.e., continuous) slope. The shadow is not continuous, due to the discontinuity of the slope. $d$ ) Isolated scene (no adjacency effects).

\subsection{Radiative budget}

Different modules and tools were added to DART for better simulating and managing the $3 \mathrm{D}$ radiative budget. DART computes the different terms of the radiative budget: absorbed energy per cell, intercepted energy per cell, scattered energy per cell and downward and upward energy on top cell faces. Here, this is illustrated by a schematic tree landscape (Figure 14). DART simulation was conducted in the near infrared with a SKYL equal to 0.2 and a sun direction $\left(\theta_{\mathrm{S}}=160^{\circ}, \phi_{\mathrm{S}}=90^{\circ}\right)$. The possibility to obtain $2 \mathrm{D}$ and $3 \mathrm{D}$ displays is very helpful for understanding the radiation interaction within the tree canopy. For example, here, larger downward radiation occurs in the air cells that are directly illuminated by the sun. This quantity can be larger than 1 because tree crowns scatter radiation through these air cells. Larger interception occurs on the illuminated tree crowns and the ground that is directly illuminated by the sun. Larger scattering occurs where interception is maximal and where local reflectance / albedo is maximal. This explains that scattering by illuminated tree crowns is larger than scattering by the illuminated ground. Indeed, in the near infrared, leaf albedo is larger than ground reflectance. It is interesting to note that the "Broadband" module of DART computes broadband radiation budget with the DART simulated narrow band radiation budgets. 


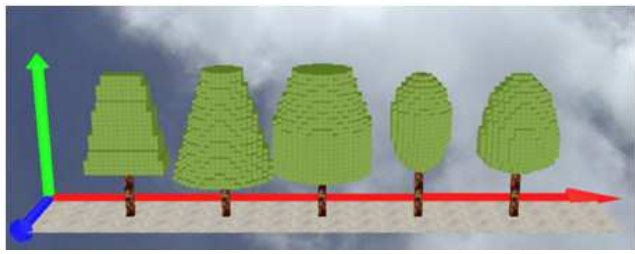

a)
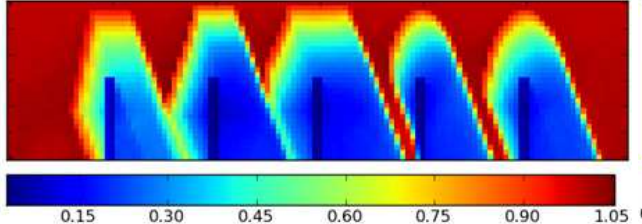

C)

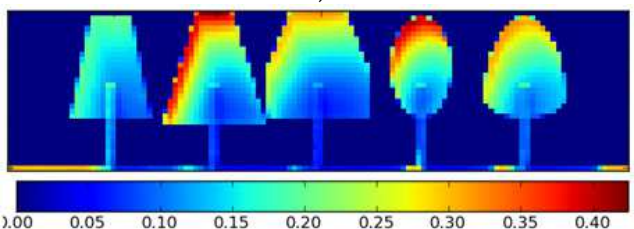

e)

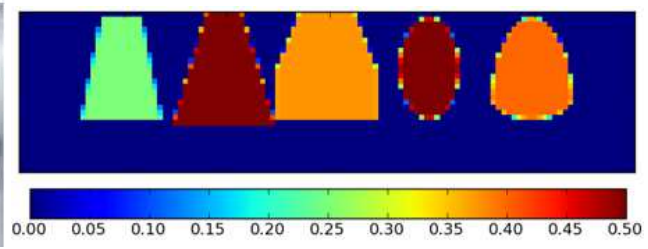

b)

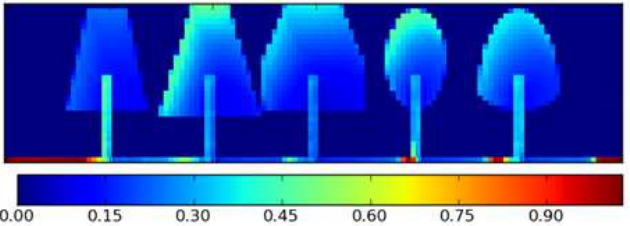

d)

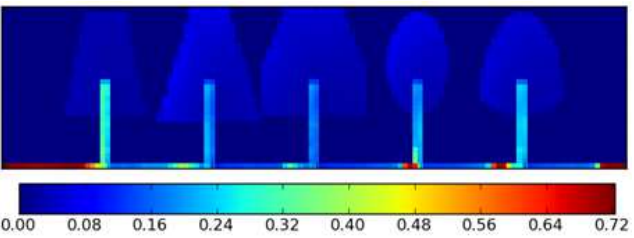

f)

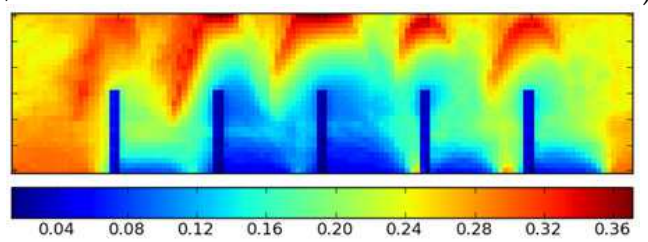

g)

Fig. 14. 3D radiative budget of a schematic tree cover. Spatial resolution is $\Delta x=0.5 \mathrm{~m}$. Ox axis is in blue color in a). Figures $b$ to g) show $2 \mathrm{D}$ distributions in the plane $x=5 \mathrm{~m}$ of the ratio "Radiometric quantity / Irradiance on the top of the landscape. b) LAI $\mathrm{I}_{\text {cell. }}$. Leaf volume density is $\mathrm{LAI}_{\text {cell. }} \Delta \mathrm{x} . \mathrm{c}$ ) Downward energy. d) Intercepted energy. e) Scattered energy. f) Absorbed energy. g) Upward energy.

\subsection{Lidar}

DART simulates lidar waveforms of urban and natural landscapes. For that, it uses a Monte Carlo method that is adapted for taking into account the usually strong anisotropy of the phase function of landscape elements. In short, the occurrence probabilities of scattering events that have the same order of magnitude are grouped for obtaining groups that have cumulated probabilities with the same order of magnitude (Gastellu-Etchegorry et al., 2010). The Monte Carlo mode in the DART model was initially developed for assessing the accuracy of DART flux tracing method, using the same simulations of landscapes. Indeed, flux tracing RT modelling requires some simplifying hypotheses for representing multiple scattering. The associated inaccuracy depends on the trade-off between the expected accuracy and computational time of simulations. The advantage of the Monte Carlo 
approach is to simulate multiple scattering processes as a succession of exactly modelled single scattering processes.

In order to simulate Lidar waveforms, the DART Lidar module works with a Gaussian spatial distribution for illumination, and a Gaussian (time) laser pulse. It is suited for small and large footprints. It is very flexible because it inherits major features of the DART model: urban and natural scenes, with topography, atmosphere, etc. Examples of waveforms are presented here for urban and natural scenes.

Figure 15 illustrates lidar modelling of a urban area that is the St Sernin district (Figure 3). It shows the image that is simulated with the flux tracing mode and the waveform that is simulated with the lidar module. As expected, the horizontal axis of the waveform gives the altitude of scene elements (buildings, vegetation, ground).

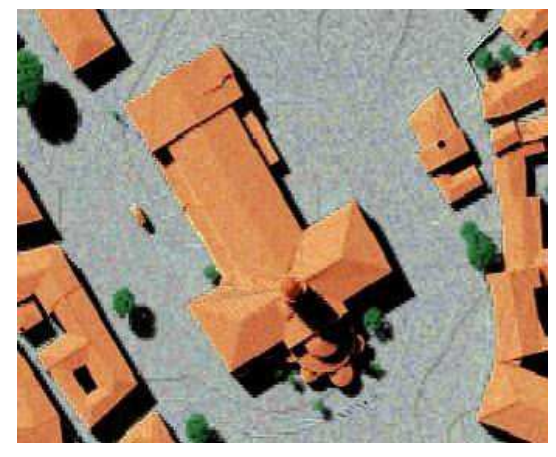

a)

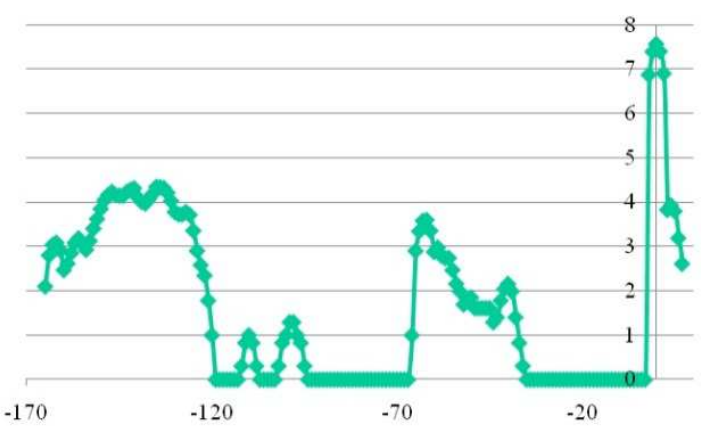

b)

Fig. 15. DART lidar simulation of the St Sernin district. a) Image simulated with the flux tracing mode. b) Waveform (Ox: time (ns), Oy: power (logarithmic). Ground gives the larger peak. Top point (Basilique) gives the $1^{\text {st }}$ signal.

Lidar simulation of a plot of citrus trees is shown here (Figure 20.a). Figure $20 \mathrm{~b}$ and c show the DART images simulated with the Monte Carlo mode and with the flux tracing mode. The 2 images are very similar. Actually, the degree of similarity depends on the number of photons that are used. As expected, the Monte Carlo mode is usually much more expensive in terms of computation time. An interesting point is that DART simulates the images of the illuminated and view footprints (Figure $20 \mathrm{~d}$ and e). This is very useful for interpreting the simulated waveform (Figure $20 \mathrm{f}$ ). As expected, the latter one shows a peak that corresponds to the ground and a peak that corresponds to the tree crowns.

The citrus waveform (Figure 16.f) being related to the LAI (Leaf Area Index) vertical profile, Ueberschlag (2010) assessed the potential of DART for retrieving the LAI of forests with an inversion procedure. Results were encouraging. As expected, similarly to the lidar response, the LAI retrieval depends a lot on the location of trees within the footprint, except if the lidar signal is uniform. For a Gaussian lidar signal, Figure 17 shows that in the case of a tree cover the LAI of which is 0.5 , the retrieved LAI can vary from 0.33 up to 0.70 , depending on the tree location within the footprint. 
a)
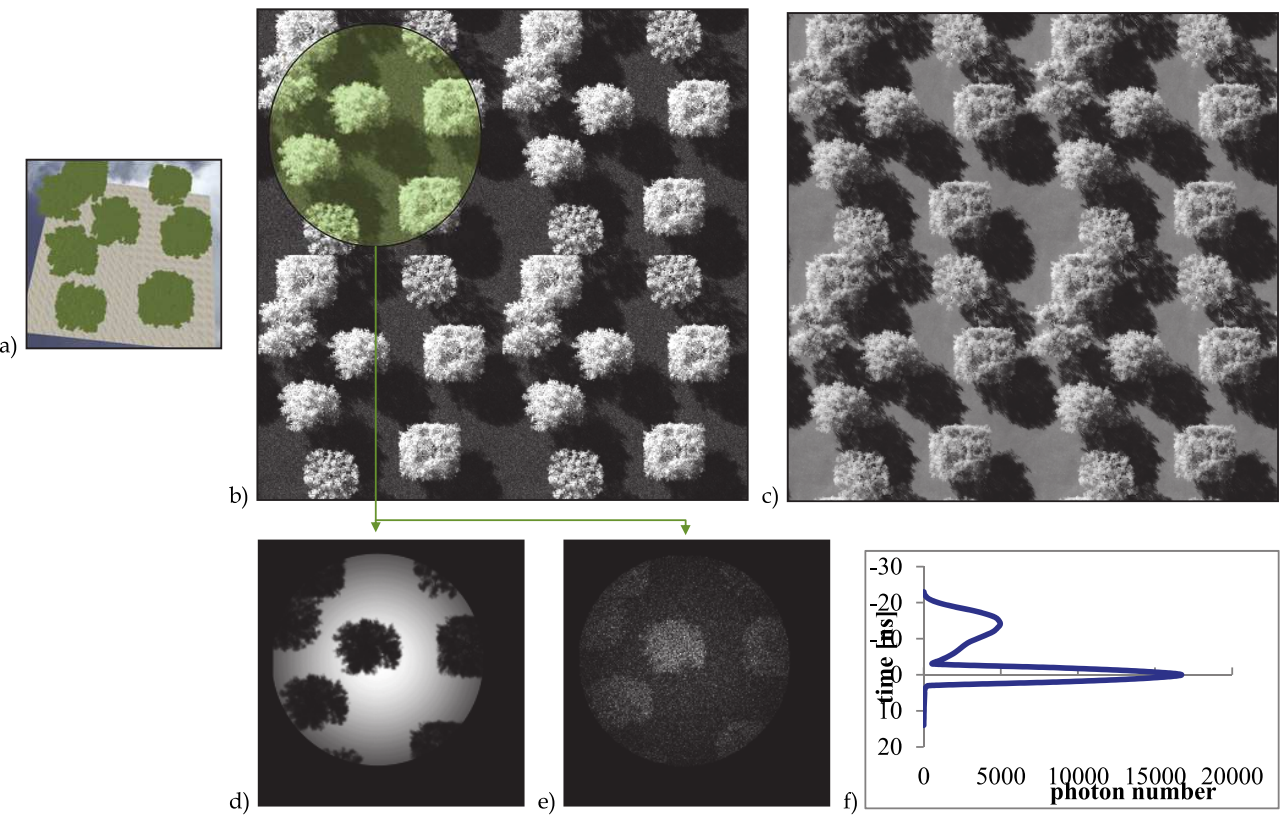

d)

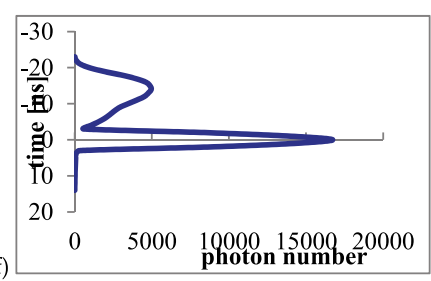

Fig. 16. Lidar simulation of citrus trees (a). Images simulated with the Monte Carlo mode (b) and the flux tracing mode (c). Images of Lidar ground (d) and view area (e) footprint. Waveform (f). The lidar has a $3 \mathrm{~ns}$ pulse duration, a $0.5 \mathrm{~ns}$ acquisition rate, a $4 \mathrm{~m}$ footprint radius and a 0.368 Gaussian illumination parameter.
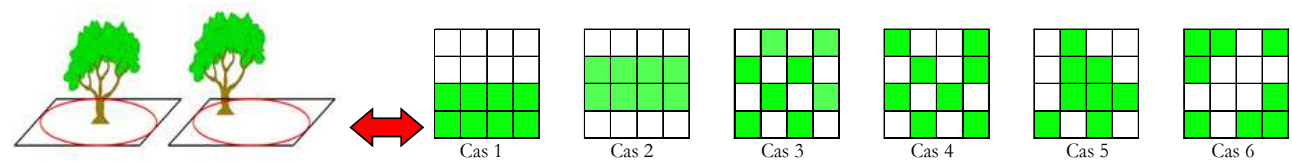

\begin{tabular}{|l|l|l|l|l|l|l|}
\hline Case & $\mathbf{1}$ & $\mathbf{2}$ & $\mathbf{3}$ & $\mathbf{4}$ & $\mathbf{5}$ & $\mathbf{6}$ \\
\hline Theoretical LAI & 0,5 & 0,5 & 0,5 & 0,5 & 0,5 & 0,5 \\
\hline Retrieved LAI - Gaussian signal & 0,52 & 0,70 & 0,50 & 0,45 & 0,64 & 0,33 \\
\hline Absolute error (\%) - Gaussian signal & 4,5 & 40,1 & $-0,2$ & $-10,4$ & 28,2 & $-33,8$ \\
\hline Retrieved LAI - Uniform signal & 0,5 & 0,5 & 0,5 & 0,5 & 0,5 & 0,5 \\
\hline Absolute error (\%) - Uniform signal & 0 & 0 & 0 & 0 & 0 & 0 \\
\hline
\end{tabular}

Fig. 17. Influence of vegetation location in the lidar footprint for retrieving forest LAI with DART.

The potential of altitude mapping was assessed. Figure 18.a shows an altitude map where the altitude of each pixel is the local higher altitude. This is called the Lidar first return altitude map. Figure 18.b is an interpolation of Figure 18.a for obtaining a 3D display. 

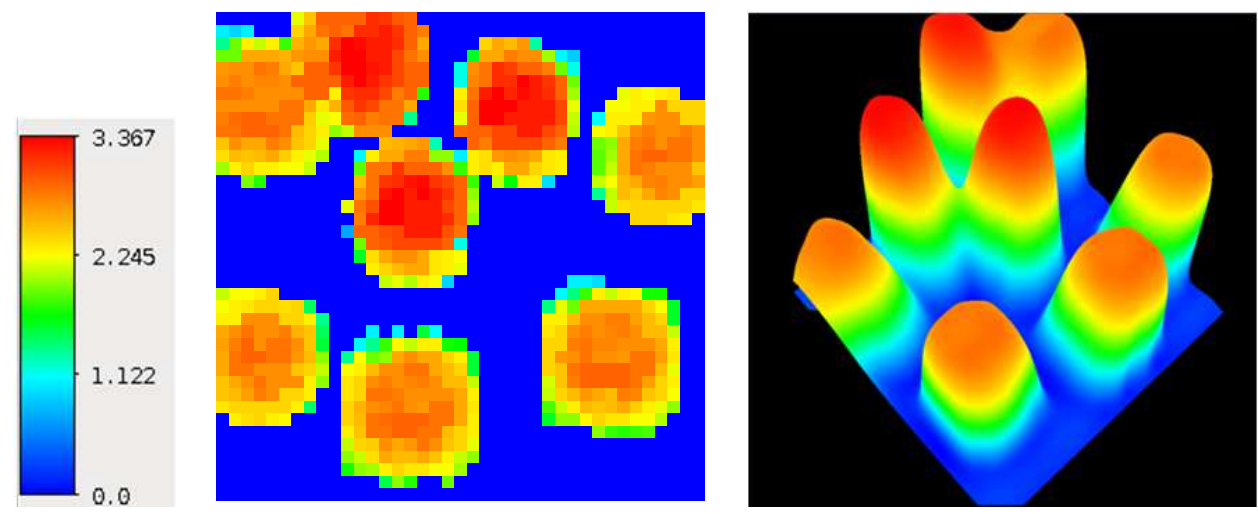

Fig. 18. Altitude mapping from DART waveforms. a) Height scale. b) Lidar first return altitude map: resolution $0.25^{\star} 0.25 \mathrm{~m}$. c) Lidar interpolated altitude 3D map

\section{Examples of applications}

\subsection{Radiance and radiative budget at continental scale}

A method was developed to create automatically for every spectral band, any date and any land area, maps of radiometric products (i.e., radiance, reflectance, brightness temperature) at a continental scale. For that, it realizes a spatial interpolation on a set of georeferenced DART products that are created by running the DART "sequencer" module with time, wavelength and land surface location used as variable parameters.

Results shown here are for the African continent, with a geostationary satellite $(35800 \mathrm{~km}$ altitude, $0^{\circ} \mathrm{N}, 17^{\circ} \mathrm{E}$ ) for 2 spectral bands (550nm: Figure 19 and Figure 20; 900nm: Figure 21 and Figure 22) at 4 dates: March 212011 (spring equinox), June 212011 (summer solstice), September 212011 (autumn equinox) and December 212011 (winter solstice), at 3 daytimes (8hUTC, 12hUTC, 16hUTC). The atmosphere is defined by a US Standard gas model and rural aerosols with a $23 \mathrm{~km}$ visibility. Simulations were carried out with the ground horizontal Lambertian "Brown to dark brown gravelly loam" from the USDA Soil Conservation Service): $\rho_{\text {ground }, 550}=0.061$ and $\rho_{\text {ground }, 900}=0.351$.

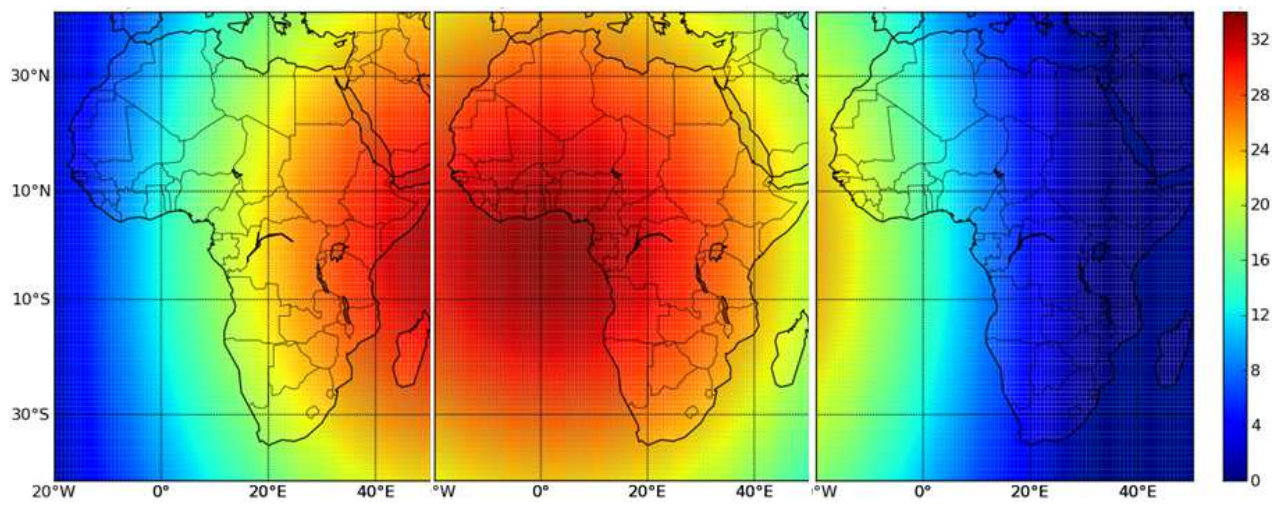

a) 


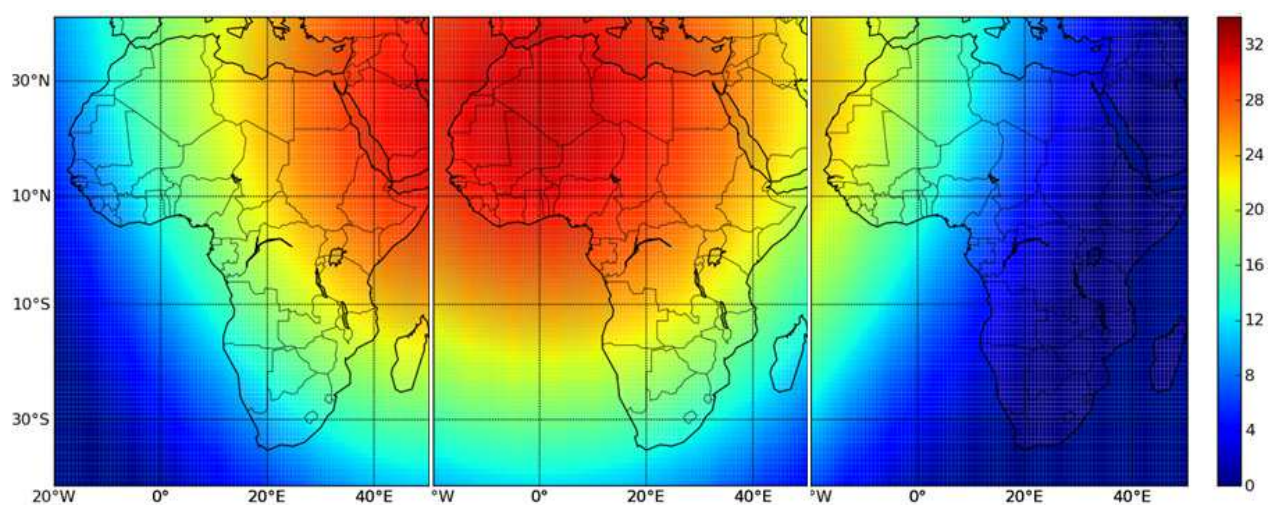

b)

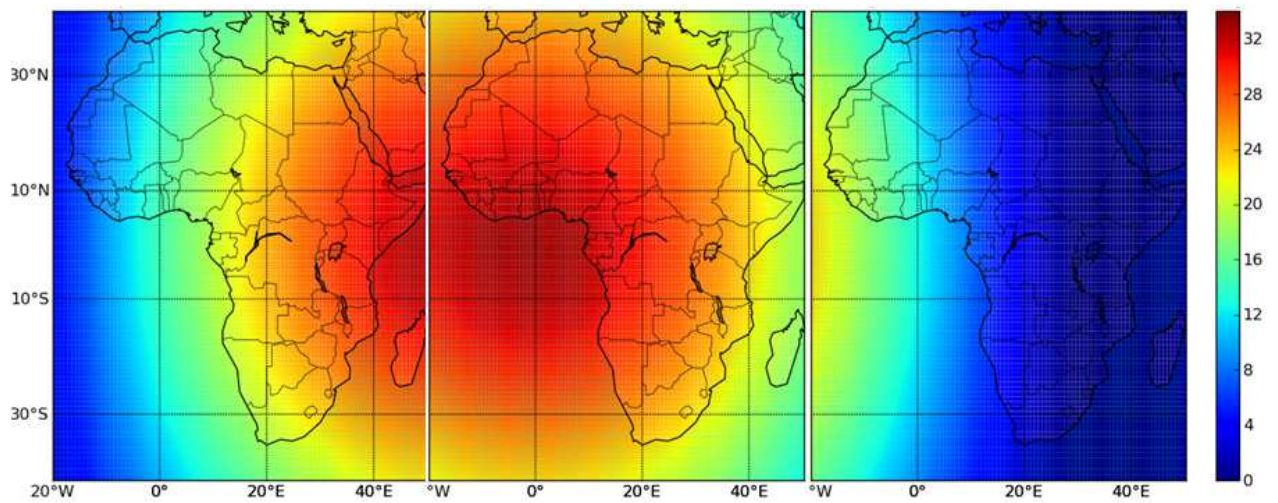

c)

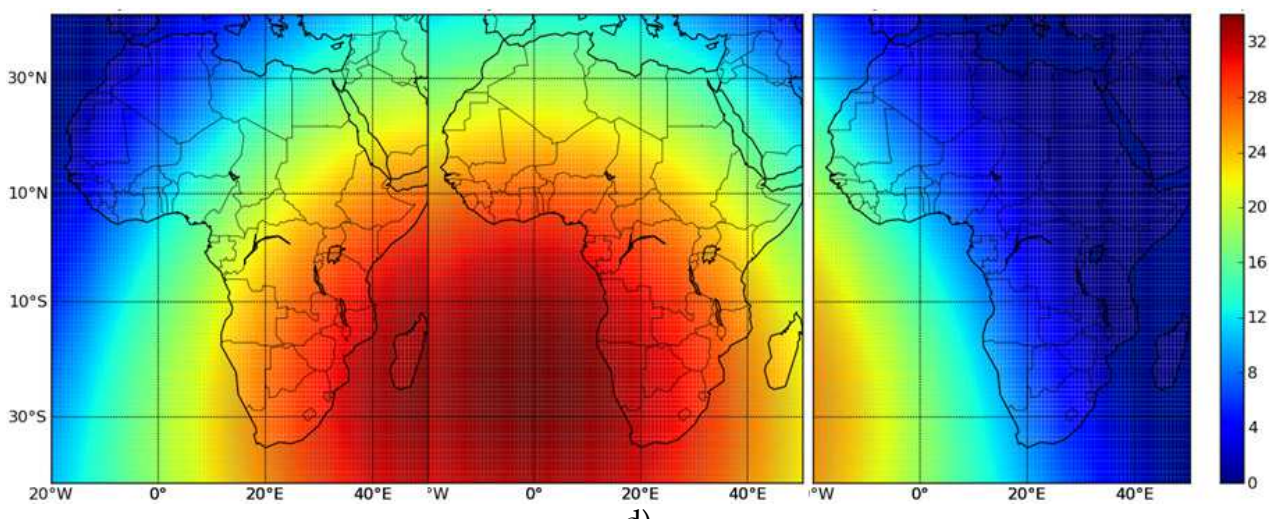

d)

Fig. 19. Seasonal 550nm BOA radiance at 8, 12 and 16h UTC. a) Spring (J=80).

b) Summer (J=172). c) Autumn (J=264). d) Winter ( $=355)$. J stands for Julian day. 


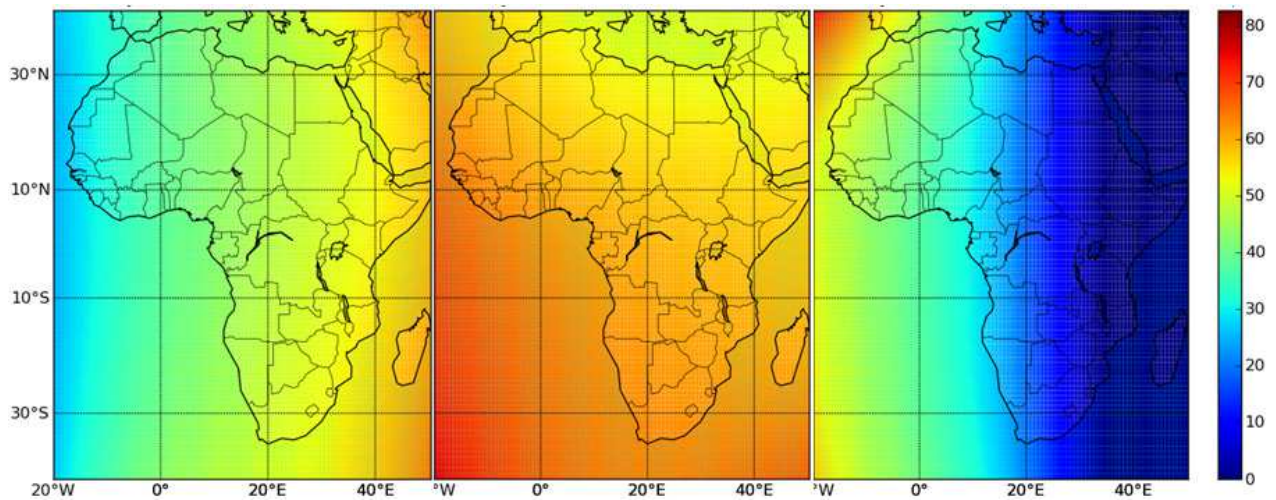

a)

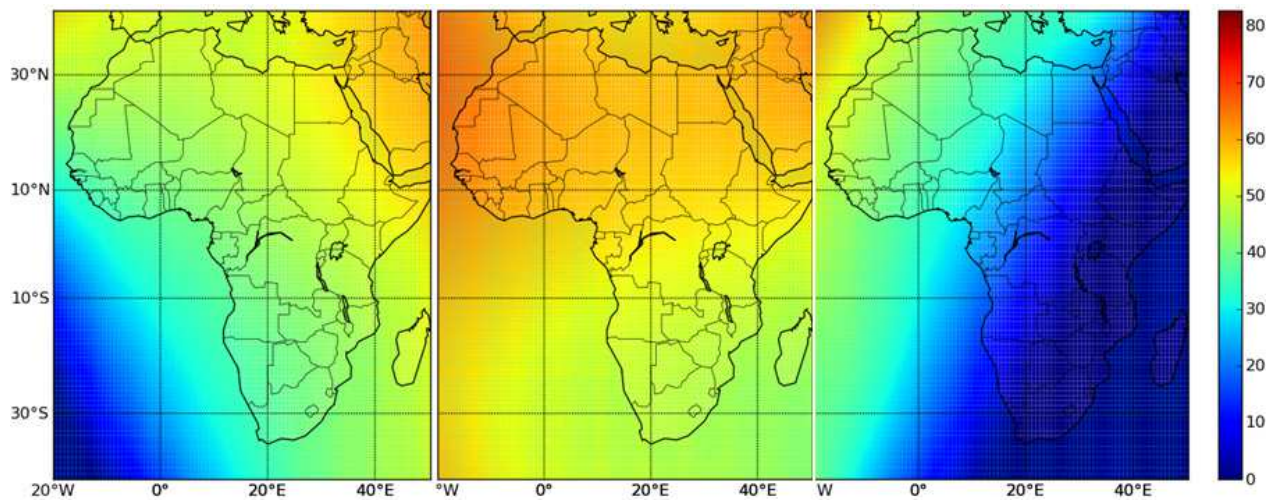

b)

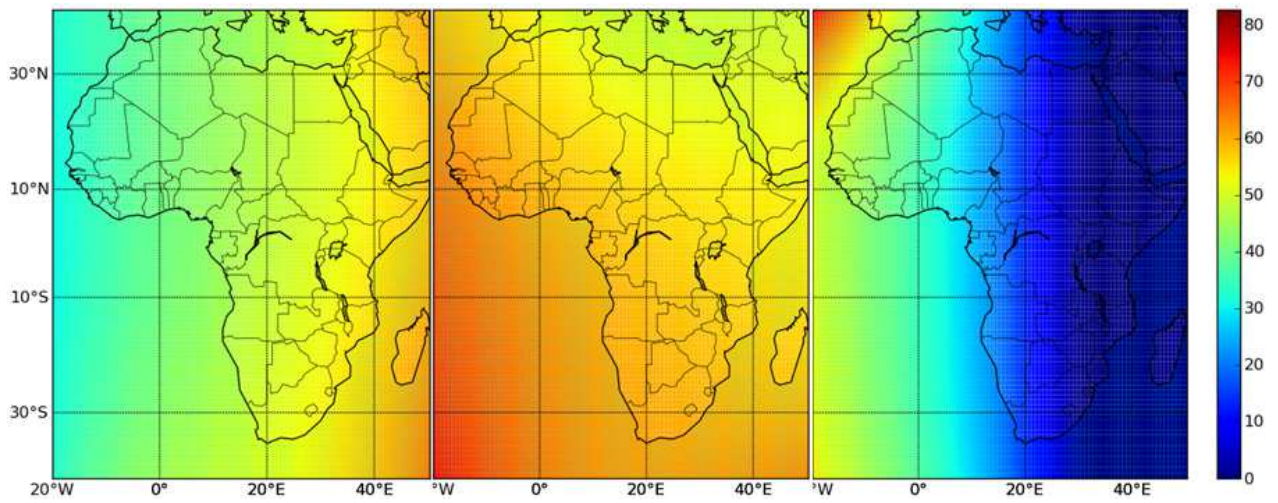

c) 


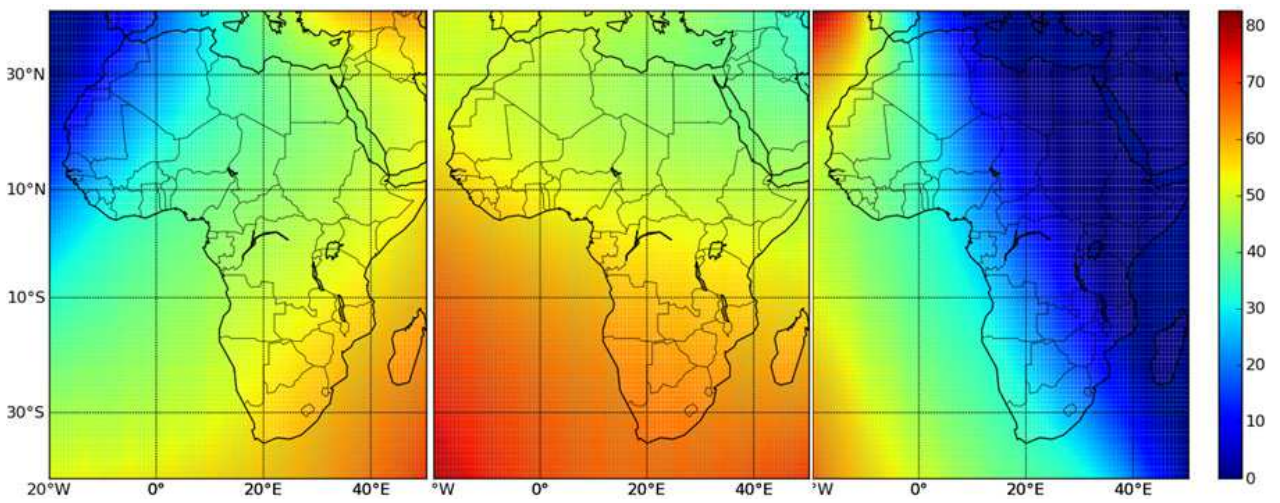

d)

Fig. 20. Seasonal TOA 550nm radiance at 8, 12 and $16 \mathrm{~h}$ UTC.

a) Spring. b) Summer. c) Autumn. d) Winter.

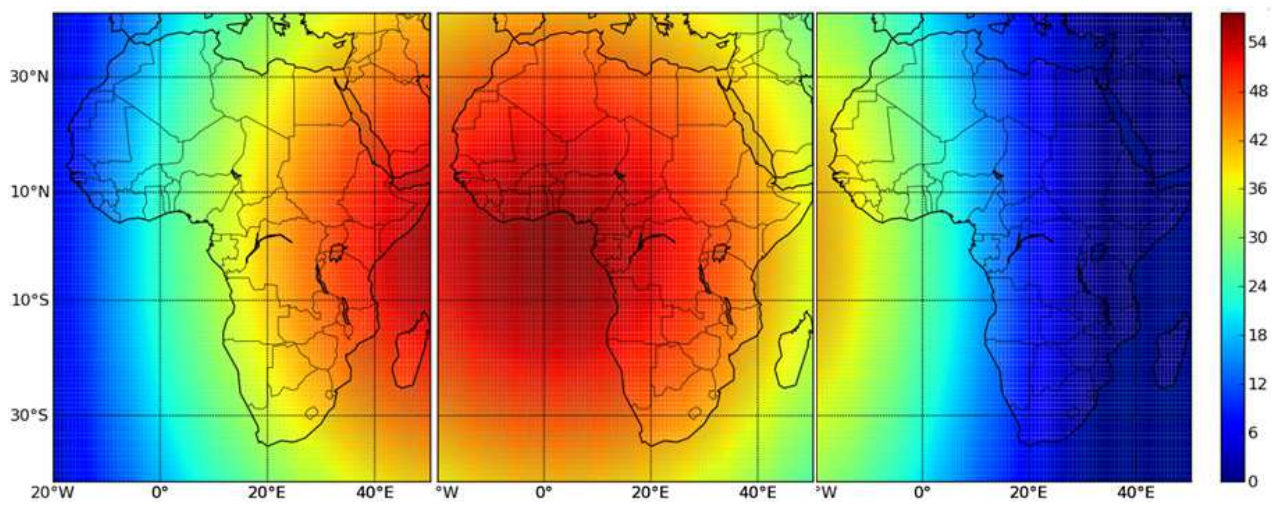

a)

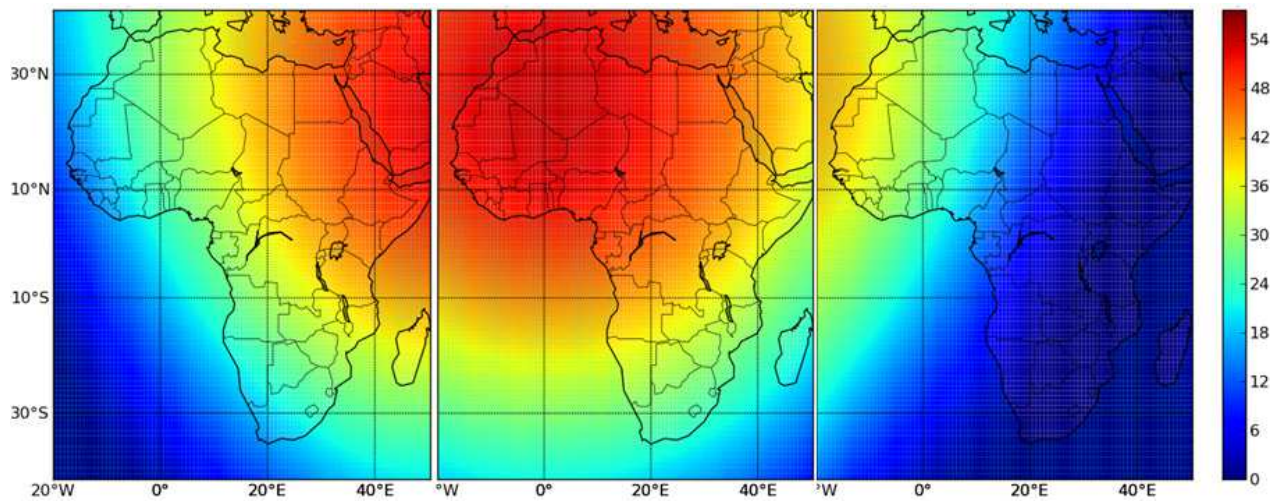

b) 


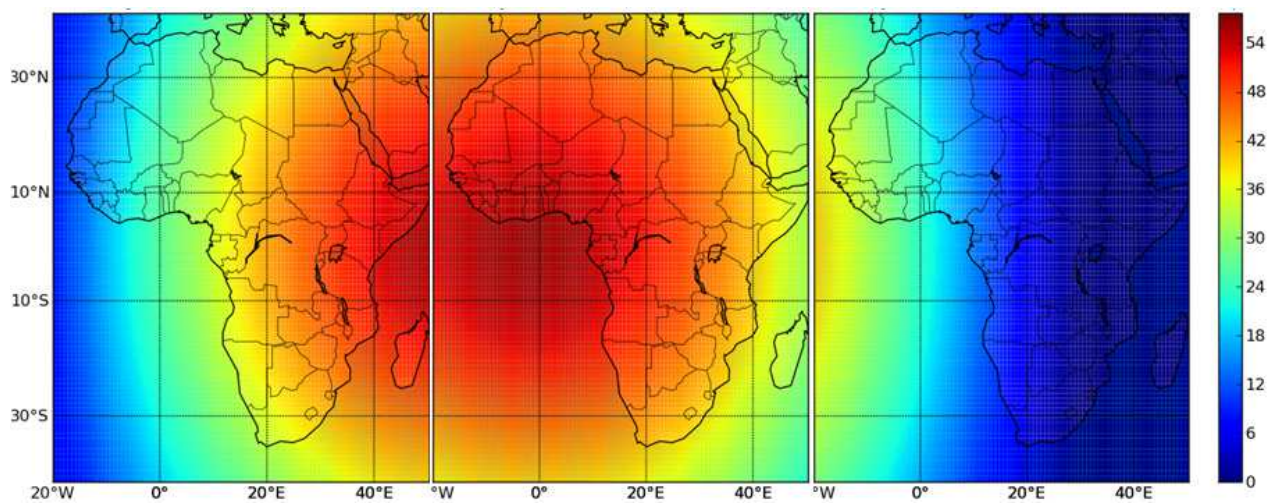

c)

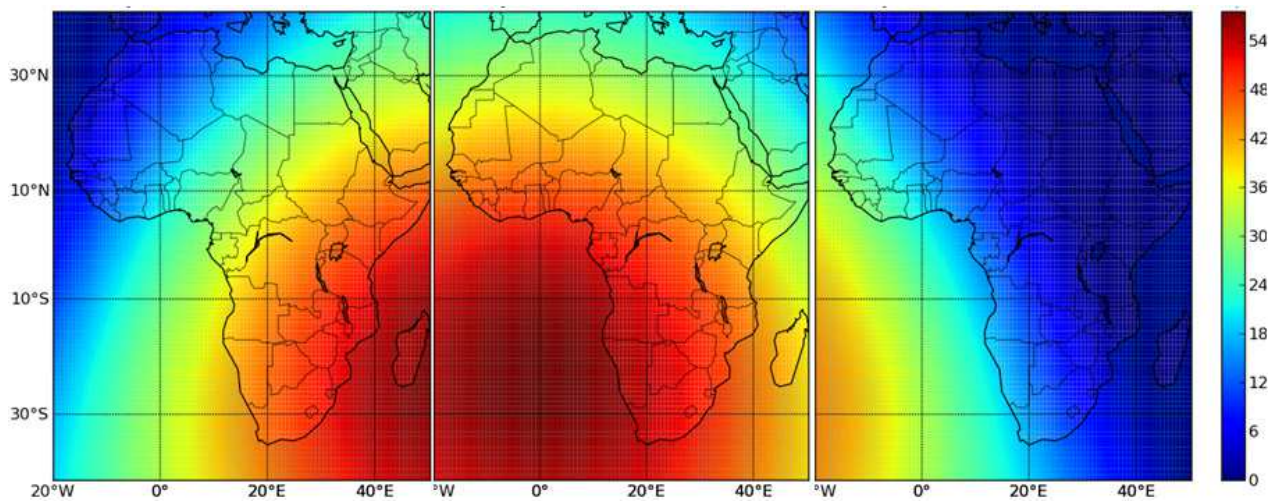

d)

Fig. 21. Seasonal BOA 900nm radiance at 8, 12 and 16h UTC. a) Spring (J=80).

b) Summer $(J=172)$. c) Autumn $(J=264)$. d) Winter $(J=355)$. J stands for Julian day.

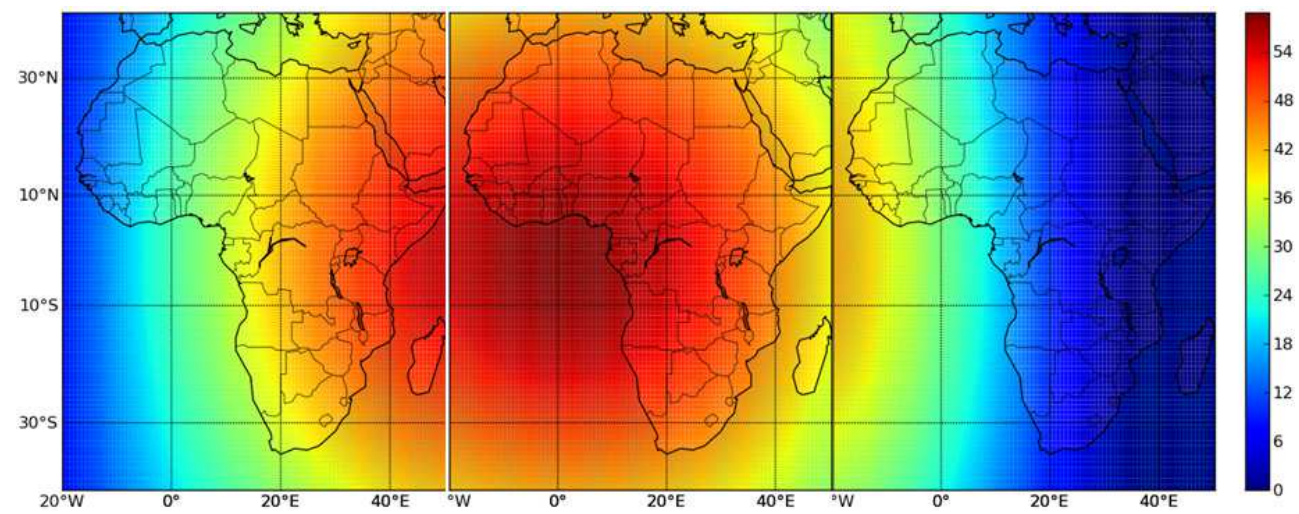

a) 


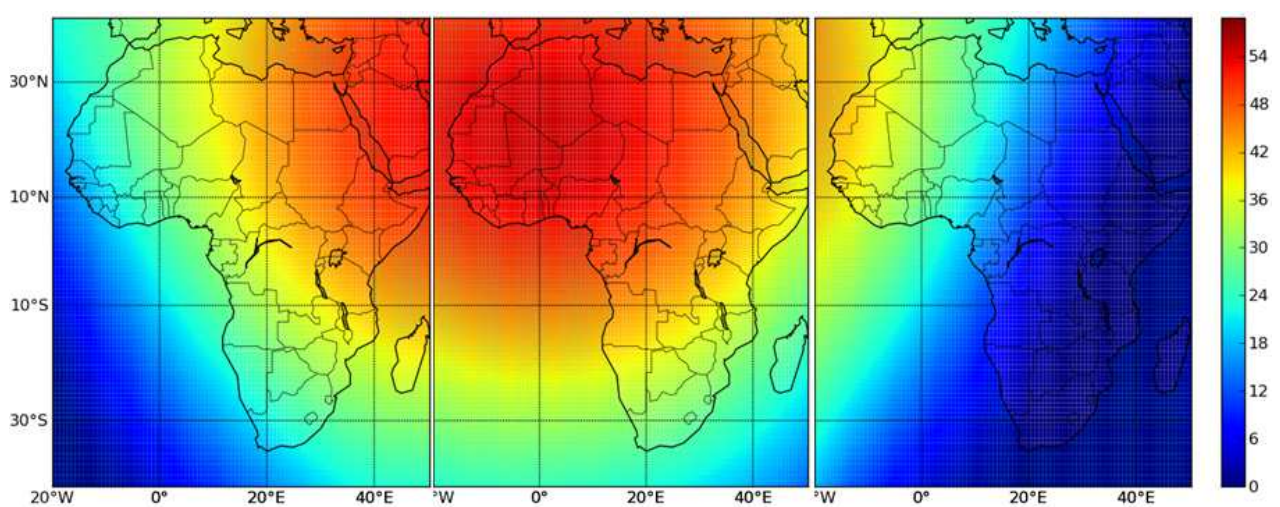

b)

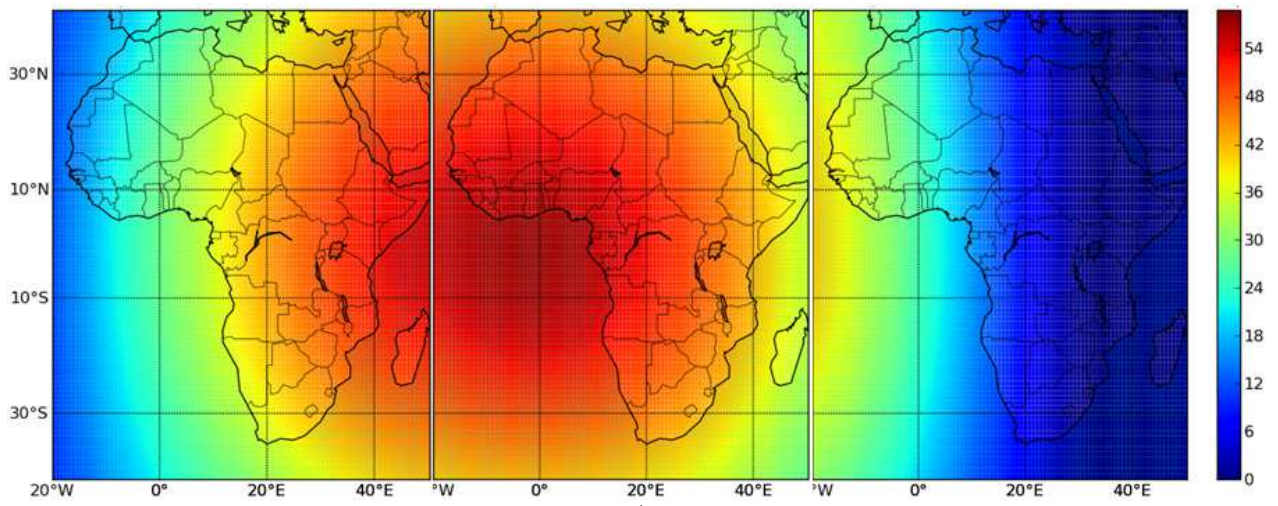

c)

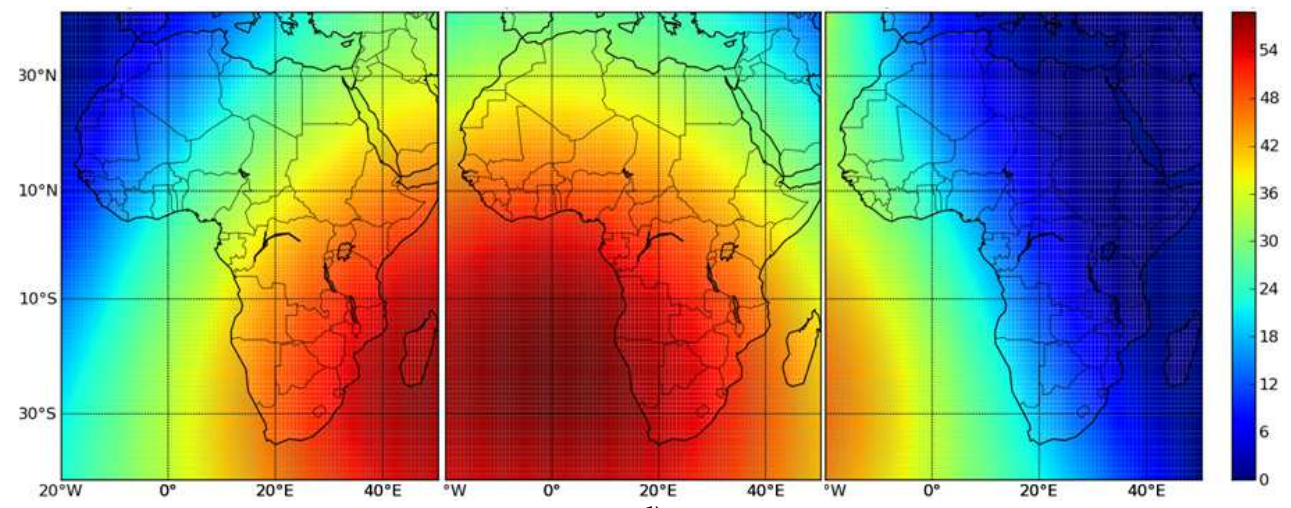

d)

Fig. 22. Seasonal TOA $900 \mathrm{~nm}$ radiance at 8,12 and $16 \mathrm{~h}$.

a) Spring (J=80). b) Summer (J=172). c) Autumn (J=264). d) Winter (J=355).

J stands for Julian day. 
In a $1^{\text {st }}$ step, the tool "Sequencer" created a grid of 20x20 DART simulations at 5 wavelengths $(0.4 \mu \mathrm{m}, 0.55 \mu \mathrm{m}, 0.67 \mu \mathrm{m}, 0.9 \mu \mathrm{m}, 1.65 \mu \mathrm{m}, 11 \mu \mathrm{m})$, with an automatic computation of the sun and view sensor angles in the local reference system, as a function of the date, time and coordinates. The grid covers almost all of the African continent: " $40^{\circ} \mathrm{S}-44^{\circ} \mathrm{N}$ " in latitude (step of $4.2^{\circ}$ ) and $" 20^{\circ} \mathrm{W}-54^{\circ} \mathrm{E}$ " in longitude (step of $3.7^{\circ}$ ). In a $2^{\text {nd }}$ step, the grid of DART products is interpolated (Python script and Numpy module). Results are displayed with a Python script and the module Basemap.

Logically, TOA radiances differ a lot from BOA radiances, because of the atmosphere. Moreover, one can note:

- $\quad$ BOA radiances are maximal in the East in the morning and West in the evening. During summer, they are larger in the Northern Hemisphere and lower in the Southern hemisphere. The situation is reversed in winter.

- TOA radiances tend to be maximal in the East in the morning and in the West in the evening. This effect is less clear than for BOA radiances. During summer, TOA radiances are larger in the Northern Hemisphere and lower in the southern hemisphere. The situation is reversed in winter.

The impact of atmosphere on TOA radiances depends on its optical thickness and phase function and on the sun and view directions. The analysis of DART images allows one to verify that this impact is not symmetric from the point of view of the satellite sensor.

The Figure 11 and Figure 12 show the maps of luminance to $900 \mathrm{~nm}$ of the African continent to 4 dates (spring, summer, autumn, winter) and 3:00 (UTC 8h, 12h UTC 16h UTC) defined above. As Figure 9 and Figure 10, this is $100 * 100$ maps obtained by interpolation of DART simulations performed for 400 geographical sites, with a Lambertian soil $(\rho=900$ 0351: "Brown to dark brown gravelly loam" of USDA Soil Conservation service) and an atmosphere "US Standard" with aerosols $23 \mathrm{~km}$ visibility. Logically, the TOA radiances and reflectances are much less affected by the atmosphere in the near infrared than in the field of green. The spatial variability of radiances is mainly due to the spatial variability of the illumination of the land surface. The geometric configuration "Sun - Earth" plays a much more important role than the geometric configuration "Sensor - Sun-Atmosphere". This is particularly the case of the phase function of gases and aerosols. This explains the much larger symmetry of the nearinfrared maps of luminance.

Figure 23 shows the annual evolution of BOA (a) and TOA (b) radiances of 6 cities: Algiers $\left(36.42^{\circ} \mathrm{N}, 3.13^{\circ} \mathrm{E}, \mathrm{UTC}+1\right)$, Cairo $\left(30.2^{\circ} \mathrm{N}, 31.13^{\circ} \mathrm{E}\right.$; UTC +2), Dakar $\left(14.4^{\circ} \mathrm{N}, 17.25^{\circ} \mathrm{W}\right.$, UTC), Pretoria $\left(25.45^{\circ} \mathrm{S}, 28.11^{\circ} \mathrm{E}, \mathrm{UTC}+2\right)$, Mogadishu $\left(2.02^{\circ} \mathrm{N} 45.21^{\circ} \mathrm{E}, \mathrm{UTC}+3\right)$, Luanda $\left(8.50^{\circ} \mathrm{S}, 13.14^{\circ} \mathrm{E}\right.$, UTC +1$)$. The evolution of the radiance $\mathrm{L}_{\text {ref }}(\mathrm{t})$ at the nadir of the satellite sensor is used as a reference. Any radiance $\mathrm{L}(\mathrm{t})$ larger than $\mathrm{Lref}_{\mathrm{r}}(\mathrm{t})$ indicates that the sensor receives light above this reference.

Figure 24 shows the $11 \mu \mathrm{m}$ TOA radiance, and its associated Brightness temperature, of the African continent. It was obtained with a ground surface characterized by an emissivity equal to 1 and a $300 \mathrm{~K}$ thermodynamic temperature, a US standard atmosphere and an atmosphere water vapor thickness equal to $1.4 \mathrm{~cm}$. The simplicity of this configuration explains the spatial symmetry of brightness and temperature. Indeed, one should take into account the actual local emissivity and thermodynamic temperature. 


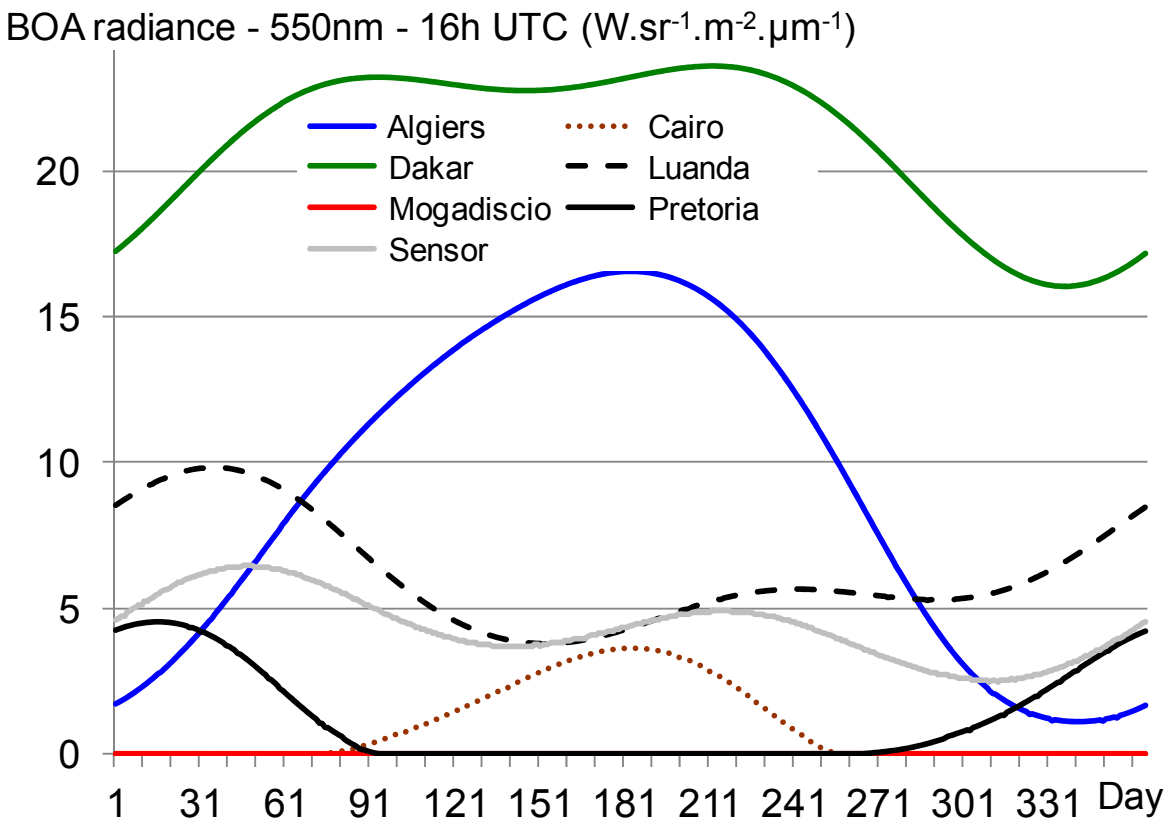

a)
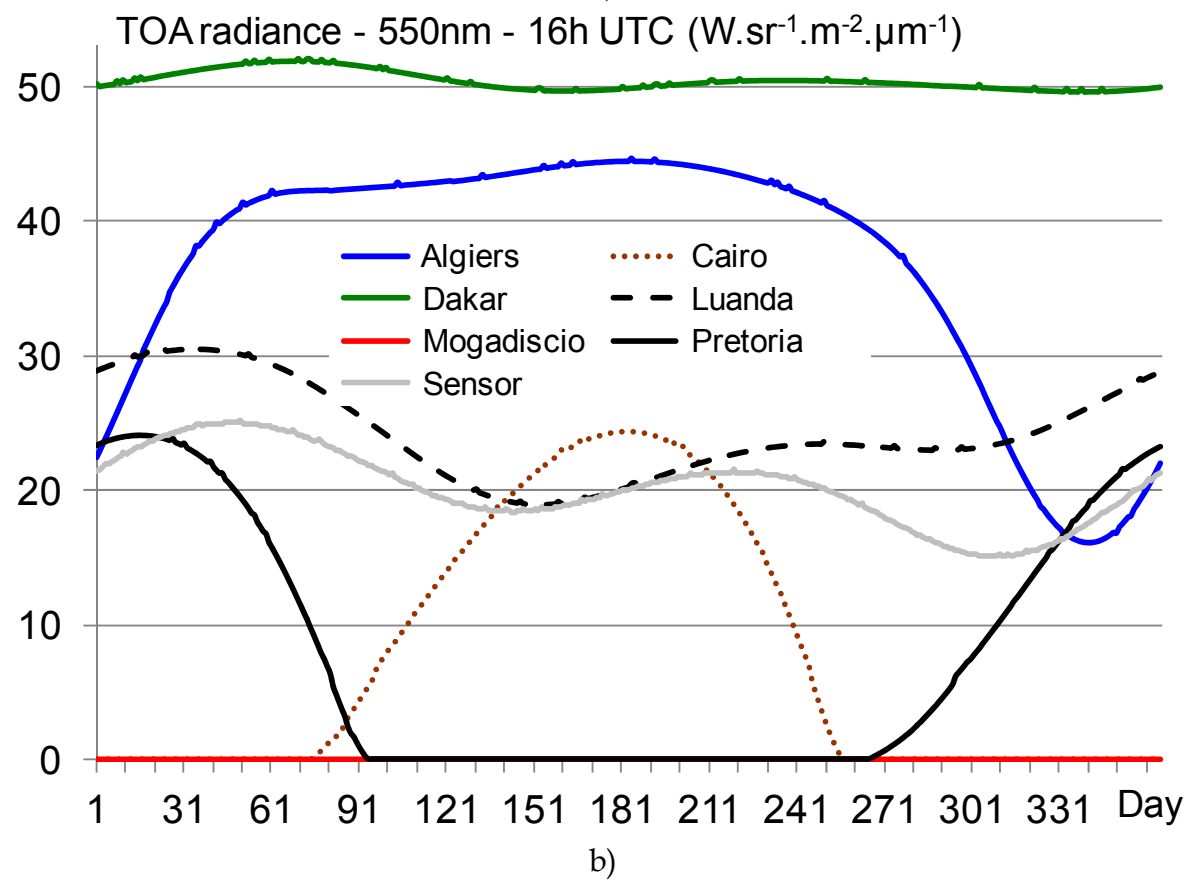

Fig. 23. 550nm BOA (a) and TOA (b) radiance of 7 cities at 16h UTC over 1 year. 


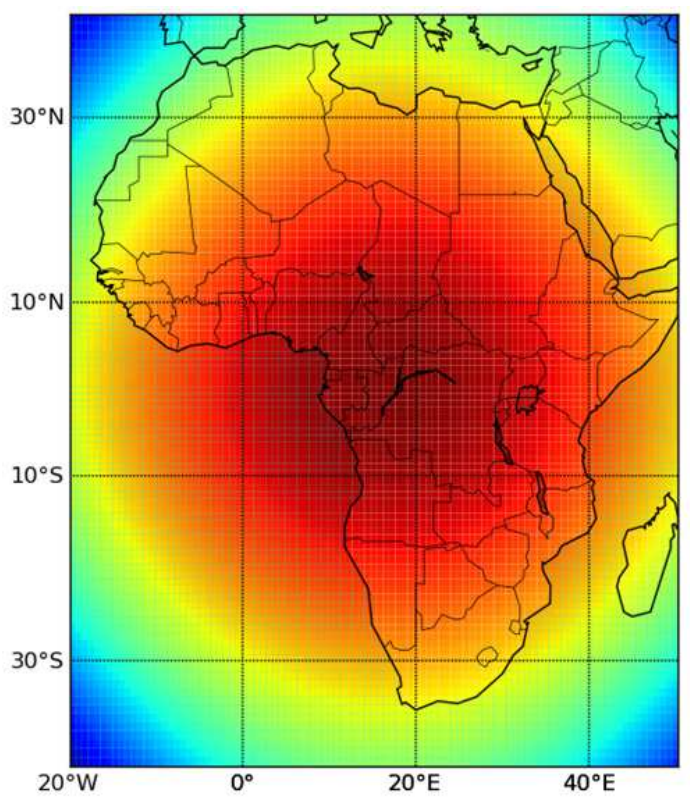

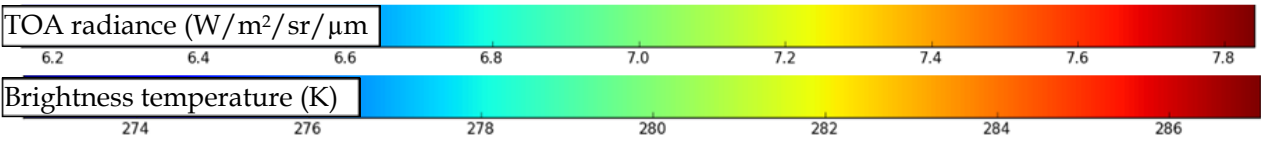

Fig. 24. 11 $\mu \mathrm{m}$ TOA radiance (a) and associated brightness temperature (b).

\subsection{DARTEB energy budget simulation}

Energy budget modeling is essential for many application domains such as the functioning of land surfaces. It is also essential for obtaining realistic simulations of satellite measurements in the thermal infrared. Indeed, it allows one to obtain the 3D distribution of thermodynamic temperature. This explains present efforts for developing a model, called DARTEB (DART Energy Budget), that simulates the 3D radiative budget of urban and vegetation surfaces, possibly with topography and atmosphere. DARTEB uses the 3-D DART radiative budget and it models all physical phenomena, other than radiation, that contribute to the energy budget: heat conduction, turbulent momentum and heat fluxes, water reservoir evolution, vegetation photosynthesis, evapotranspiration. The example shown here is for a urban canopy. In that case, non-radiative mechanisms that contribute to the energy budget are simulated with the equations of the TEB urban surface scheme (Masson, 2000). This scheme works with a canyon geometry. For example, turbulent fluxes and conduction are computed with classical boundary-layer laws using equations of TEB. 
Conversely to the TEB scheme, DARTEB uses a 3-D cell discretization, in addition to the layer discretization of roofs, walls and roads: modeling is conducted on a DART cell per cell basis. As a result, fluxes are computed for each point of the 3-D scene. The transfer coefficients for turbulent heat and moisture fluxes are identical; they differ from the transfer coefficients for momentum fluxes. For DARTEB, the urban canopy is simulated as the juxtaposition of urban street canyons. Here, we worked with a single urban canyon, for remaining in the validity domain of TEB equations (Masson, 2000). Each surface type (wall, soil, roof) is discretized into several layers for simulating the conduction fluxes to or from the ground and building interiors. The number of layers for road, wall and roof can differ. A minimal number of three layers is advised because temperature gradients can be large and because of the multi-layer structure of the walls and roofs.

DARTEB uses a prognostic approach for assessing the 3D radiative budget distribution, and consequently the 3D temperature distribution. Temperature values at time " $\mathrm{k}-1$ " are used for computing the 3D TIR and energy budgets at time " $k "$, which allows one to compute the 3D temperature distribution at time " $\mathrm{k}$ ", using the 3D visible and NIR radiation budget at time "k" (Figure 25). DART simulations in the short wave domain are conducted during the day period only.

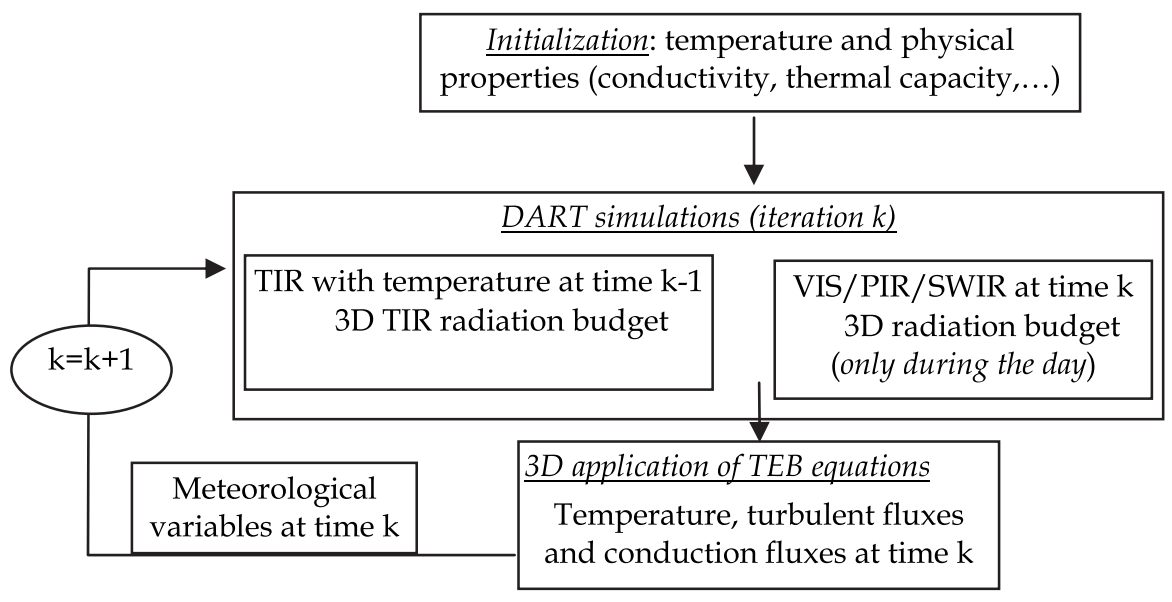

Fig. 25. Diagram of DARTEB model.

The validity of DARTEB was tested against TEB simulations and against in situ temperature measurements during the Capitoul campaign (Albinet, 2008). DARTEB proved to be coherent with TEB and with measurements. Here, this is illustrated by the comparison of simulated and measured temperatures during 3 days, from July 14 to July 17, 2004, for the Alsace Lorraine street (South-North orientation) and La Pomme street (South East - North West orientation) in Toulouse.

The simulated and measured road temperature curves are very similar (Figure 26.a). As expected, road temperature values increase during the day. There are 3 major differences 


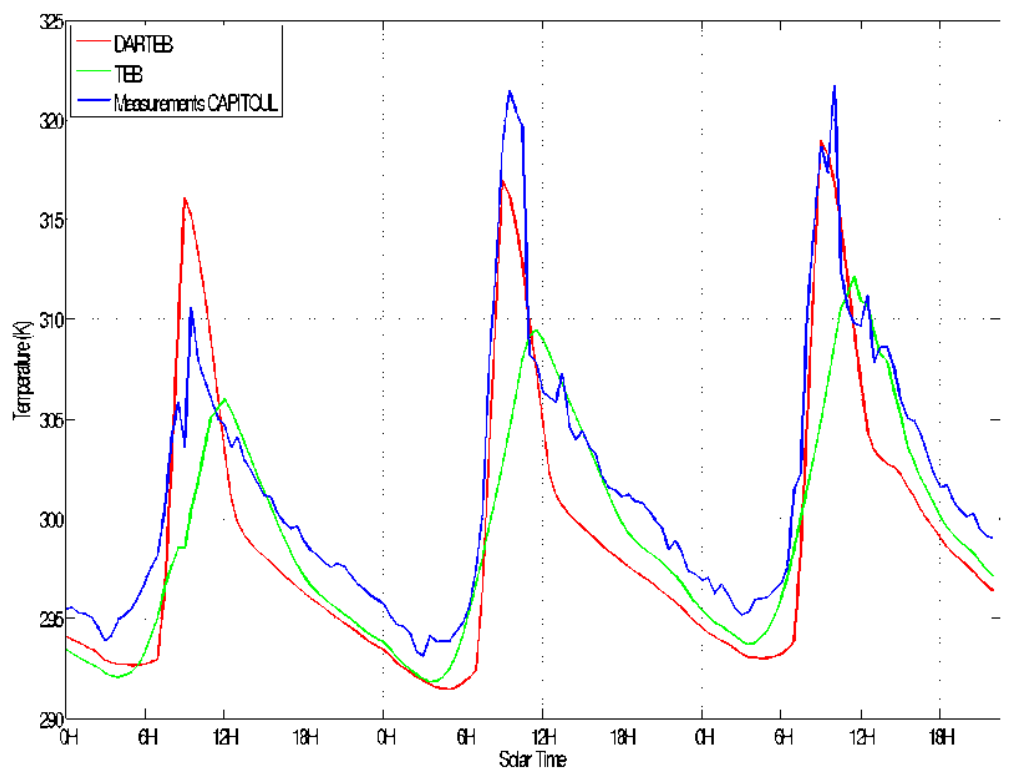

a)

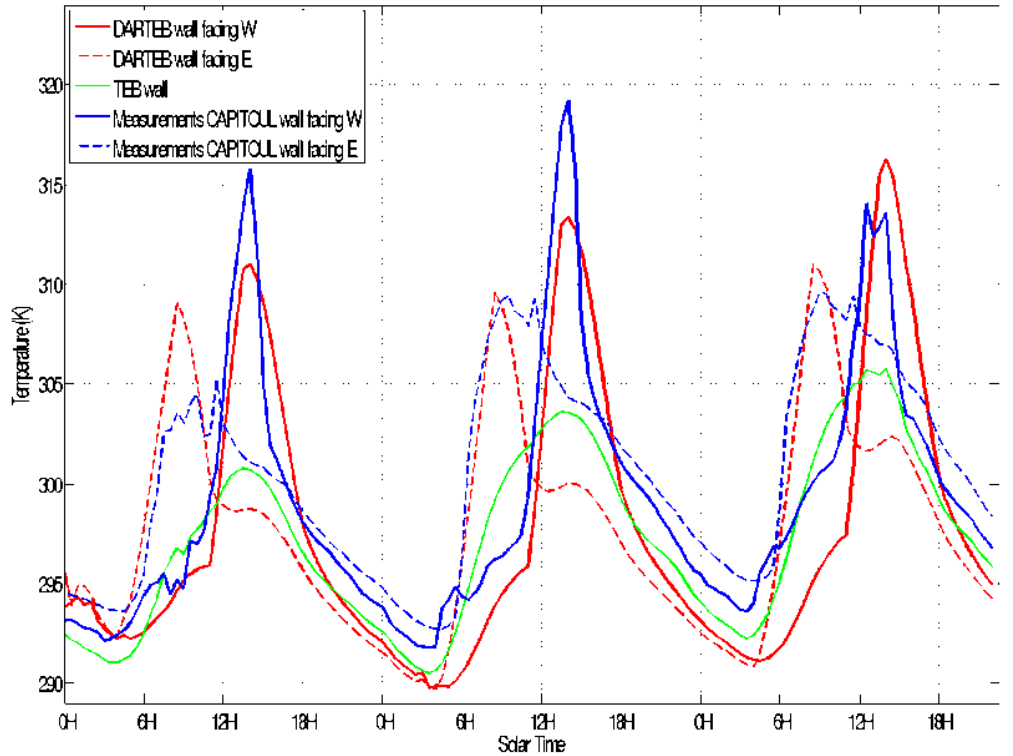

b)

Fig. 26. Comparison of temperature measurements (blue) with DARTEB (red) and TEB (green) simulations. July 14-16 2004. a) Road of La Pomme street (Toulouse) with a south East - North West orientation. b) Walls of Alsace Lorraine street (Toulouse) with a SouthNorth orientation. The 2 walls are facing West and East directions, which implies different thermal behaviors. 
between DARTEB and TEB simulations. (1) Maximal DARTEB temperatures are larger than maximal TEB temperatures. (2) Maximal DARTEB temperatures occur before midday conversely to maximal TEB temperatures that occur at midday. (3) DARTEB curves are smoother than TEB curves. These differences are mostly explained by the fact that DARTEB takes into account the 3-D nature of the canyon geometry, conversely to TEB. Indeed, the TEB model works with a mean canyon that corresponds to an azimuthally averaged street direction. Thus, TEB temperatures are mean values, which explains that their time variations are smoothed, with maximal values at midday. Actually, due to the South East North West orientation of La Pomme street, the maximum road illumination occurs before midday and the maximal road illumination is larger than the mean road illumination for all possible canyon orientations. This is well simulated by DARTEB. Each morning, the measured and DARTEB temperature values display nearly the same sharp increase. However, each afternoon, DARTEB temperature values decrease faster than TEB and the observed temperature values. Several factors can explain the differences between the DARTEB and observed temperature values. For example, an inaccurate road heat capacity implies an inaccurate conduction flux, and an inaccurate road roughness length tends to imply an inaccurate heat flux, which tends to lead to inaccurate road temperature values. Another possible explanation can come from an inaccurate simulation of the proportions of the 2 components of the canyon illumination: sun and sky illumination. Here, these components are driven by the atmosphere optical depth and sun zenith angle. However, in the absence of measurements, the atmosphere optical depth is assumed to be constant.

The wall (Figure 26.b) DARTEB and measured temperature values tend to be very close, both for the wall facing West, and for the wall facing East. They differ from TEB temperature values because TEB gives a mean value for the 2 walls of the canyon. Account of wall orientation is important because walls with different sun illumination have different temperature values, with larger values during daytime for walls with best sun orientation. As expected, DARTEB maximal temperature values occur in the morning for the wall facing East, and in the afternoon for the wall facing West. This is not the case with TEB maximal temperature values; they occur at midday due to the fact that TEB works with azimuthally averaged canyons. This explains also that TEB temperature values are too small. These examples stress the impact of 3-D architecture on temperature distributions.

\section{Concluding remarks}

Some major and recent improvements of DART radiative transfer model are presented in this paper. After years of development DART has reached the stage of a reference model in the field of remote sensing in the optical domain. It was patented (PCT/FR 02/01181) in 2003. It is used in more than 80 Space Centers, Universities and Research Centers: NASA GSFC (USA), the King's College (UK), Research center of Meteo France, IRD (France), Virginia University (USA), Instituto de Agricultura Sostenible (Spain), etc. Paul Sabatier University (France) provides free licenses for scientific works (www.cesbio.ups-tlse.fr), for windows and Linux systems. Its domains of application are centered on remote sensing applications for land surfaces (forestry, agriculture, urbanism,...), on the preparation of future satellite sensors and on the improvement of the use of already available satellite data. It is also more and more used for radiation budget in urban and natural environments, with 
the objective to couple it with functioning models. Moreover, DART is also more and more used in the field of education for teaching the physical bases of remote sensing and radiative budget. Generally speaking, the possibility to create very easily urban and natural landscapes is very interesting for scientists who want assess remote sensing measurements in any experimental and instrument conditions.

Today, work continues for improving DART, for both the physics, functionalities and computer science aspects. Present ongoing improvements concern the storing and manipulation of LUTs as actual databases, the inversion of satellite images, the Lidar and the design of a new GUI. Planned improvements concern the modeling of the EarthAtmosphere system in presence of clouds. DART will not simulate RT within clouds. These will be considered as interfaces with specific optical properties and geometric dimensions. Other major planned improvements will be the simulation of RT adapted to water bodies and to fire.

\section{Acknowledgement}

This work was supported by Region Midi Pyrénées and by the Centre National d'Etudes Spatiales (CNES) in the frame of the project "High spatial resolution of the land surfaces with a geostationary satellite". Authors are also thankful to the CESBIO (Space Center for Biosphere Studies) research team that contributes to the development of DART.

\section{Annex: Computation of view incidence angle}

For an Earth target T and a satellite sensor S, DART computes the local incidence angle $\alpha$, the sensor off-nadir direction $\beta$ and the sun azimuth angle in the Earth surface reference system as a function of the locations (latitude, longitude, altitude) of $T$ and $S$, with the assumption that the Earth is an ellipsoid.

Let us note $\mathrm{O}$ the Earth center and $\mathrm{Oz}$ the "South - North" axis perpendicular to the equatorial plane. The axis $\mathrm{Ox}$ is perpendicular to $\mathrm{Oz}$ and is in the plane $\{\overrightarrow{\mathrm{OT}}, \mathrm{Oz}\}$. The plane that contains the target $\mathrm{T}$ and the vertical $\mathrm{Oz}$ is an ellipse defined by $\frac{x^{2}}{a^{2}}+\frac{z^{2}}{b^{2}}=1$, with $\mathrm{a}=6378.136 \mathrm{~km}$ and $\mathrm{b}=6356.751 \mathrm{~km}$. The earth eccentricity is: $e=\frac{\sqrt{a^{2}-b^{2}}}{a}$ e. At local latitude Lat, the local Earth radius is: $R($ Lat $)=\frac{b}{\sqrt{1-e^{2} \cdot \cos ^{2}(\text { Lat })}}$

Any point $\mathrm{M}$ on the ellipsoid is characterized by (Lat $\mathrm{m}_{\mathrm{m}}$ Long $\left.\mathrm{m}_{\mathrm{m}}\right)$ or by the angles $\left(\gamma_{\mathrm{m}}, \phi_{\mathrm{m}}\right)$ in the Earth spherical coordinate system (Figure 26):

Lat $\in\left[90^{\circ} \mathrm{S} 90^{\circ} \mathrm{N}\right] \Leftrightarrow \gamma \in\left[0180^{\circ}\right]\left(\gamma=0 \Leftrightarrow\right.$ Lat $\left.=90^{\circ} \mathrm{N}\right)$

Long $\in\left[\begin{array}{ll}0 & 360^{\circ}\end{array}\right] \Leftrightarrow \phi \in\left[\begin{array}{ll}0 & 360^{\circ}\end{array}\right]$

Let $R_{\text {target }}$ and $R_{\text {sat }}$ be the Earth radius at points $t$ and $s$ that are the vertical projection on the Earth ellipsoid of target $T$ and satellite $S$ respectively. Points $t$ and $s$ are defined by:

- $\quad t$ : Lat $t$, Long . Target $\mathrm{T}$ altitude is $\mathrm{H}_{\text {target }}$ above the Earth surface

- $\quad$ s: Lat sat $_{\text {, Long }}$ sat. Satellite altitude is $\mathrm{H}_{\text {sat }}$ above the Earth surface

Zenith angles of vectors $\overrightarrow{\mathrm{OS}}$ and $\overrightarrow{\mathrm{OT}}$, with $\mathrm{s}$ and $\mathrm{t}$ the vertical projections of points $\mathrm{S}$ and $\mathrm{T}$, are:

$$
\gamma_{\mathrm{sat}}=\frac{\pi}{2}-\text { Lat }_{\mathrm{sat}} \text { and } \gamma_{\mathrm{t}}=\frac{\pi}{2}-\text { Lat }_{\mathrm{t}} \text { respectively (in radians) }
$$




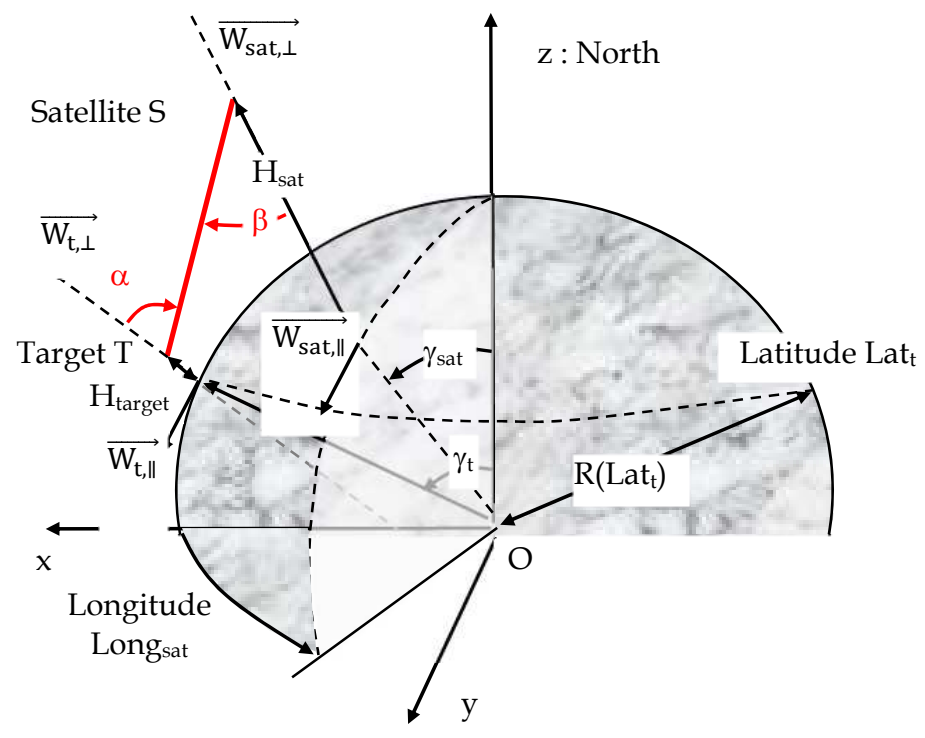

Fig. 27. Geometric configuration "Satellite - Earth scene", for an ellipsoidal Earth.

In the pre-defined Earth system, point $t$ is defined by $\overrightarrow{\mathrm{OT}}\left\{\mathrm{R}_{t}\left(\gamma_{t}\right) \cdot \sin \left(\gamma_{t}\right), 0, \mathrm{R}_{t}\left(\gamma_{t}\right) \cdot \cos \left(\gamma_{t}\right)\right\}$. The unit vector $\overrightarrow{\mathrm{W}_{\mathrm{t}, \|}}$ of the tangent to the ellipse along the axis $\mathrm{Ox}$ at point $\mathrm{t}$ is defined by:

- $\quad \mathrm{z}_{\mathrm{t}} \neq 0: \overrightarrow{\mathrm{W}_{\mathrm{t}, \|}}\left\{1,0,-\frac{b^{2}}{a^{2}} \frac{x_{t}}{z_{t}}\right\} \cdot \frac{1}{\left.\sqrt{1+\left[\frac{b^{2} x_{t}}{a^{2}} z_{t}\right.}\right]^{2}}$ We note that $\overrightarrow{\mathrm{W}_{\mathrm{t}, \|}}\{0,0,1\}$ if $\mathrm{x}_{\mathrm{t}}=0$ (i.e., $\mathrm{z}_{\mathrm{t}}=\mathrm{b}$ )

- $\quad z_{t}=0$ (i.e., $\left.x_{t}=a\right): \overrightarrow{W_{t, \|}}\{1,0,0\}$

The unit vector $\overrightarrow{\mathrm{W}_{\mathrm{t}, \perp}}$ perpendicular to the ellipse at point $\mathrm{t}$ is: $\overrightarrow{\mathrm{W}_{\mathrm{t}, \perp}}\left\{1,0,-\frac{a^{2}}{b^{2}} \frac{z_{t}}{x_{t}}\right\} \cdot \frac{1}{\sqrt{1+\left[\frac{a^{2} z_{t}{ }^{2}}{b^{2} x_{t}}\right]^{2}}}$

Let $\gamma_{t}^{*}$ be the zenith angle of $\overrightarrow{\mathrm{W}_{\mathrm{t}, \perp}}$ in the Earth system. It allows one to compute $\overrightarrow{\mathrm{OT}}$ : $\overrightarrow{\mathrm{OT}}=\overrightarrow{\mathrm{Ot}}+\left\{\mathrm{h}_{\mathrm{t}} \cdot \sin \left(\gamma_{t}^{*}\right), 0, \mathrm{H}_{\mathrm{t}} \cdot \cos \left(\gamma_{t}^{*}\right)\right\}$ with $\cos \left(\gamma_{t}^{*}\right)=\overrightarrow{\mathrm{W}_{\mathrm{t}, \perp}} \cdot \overrightarrow{\mathrm{W}_{\mathrm{z}}}$ and $\gamma_{t}^{*} \in\left[\begin{array}{ll}0 & \pi\end{array}\right]$

Similarly, for point s, we have: $\overrightarrow{\mathrm{Os}}\left\{\mathrm{R}_{\text {sat }} \cdot \sin \left(\gamma_{\text {sat }}\right) \cdot \cos \left(\right.\right.$ Long $_{\text {sat }}-$ Long $\left._{t}\right), \mathrm{R}_{\text {sat }} \cdot \sin \left(\gamma_{\text {sat }}\right) \cdot \sin \left(\right.$ Long $_{\text {sat }}$ Long $\left.\left._{\mathrm{t}}\right), \mathrm{R}_{\text {sat }} \cdot \cos \left(\gamma_{\text {sat }}\right)\right\}$ 
Let $\overrightarrow{\mathrm{W}_{\mathrm{sat}, \perp}}$ be the perpendicular to the ellipse at point $\mathrm{s}$ in the Earth system. In the local reference:

$$
\left(Z-Z_{\text {sat }}\right)=\frac{a^{2} \cdot z_{\text {sat }}}{b^{2} \cdot X_{\text {sat }}}\left(X-X_{\text {sat }}\right) \Rightarrow \overrightarrow{\mathrm{W}_{\text {sat }, \perp}}\left\{1,0,-\frac{a^{2}}{b^{2}} \frac{z_{\text {sat }}}{X_{\text {sat }}}\right\} \cdot \frac{1}{\sqrt{1+\left[\frac{a^{2} \cdot z_{\text {sat }}}{b^{2} \cdot X_{\text {sat }}}\right]^{2}}} \text { if } \mathrm{X}_{\text {sat }} \neq 0 .
$$

with $X_{\text {sat }}^{2}=x_{\text {sat }}^{2}+y_{\text {sat }}^{2}=\mathrm{R}^{2}\left(\right.$ Lat $\left._{\text {sat }}\right) \cdot \sin ^{2}\left(\gamma_{\text {sat }}\right), \mathrm{x}_{\text {sat }}=\mathrm{R}\left(\right.$ Lat $\left._{\text {sat }}\right) \cdot \sin \left(\gamma_{\text {sat }}\right) \cdot \cos \left(\right.$ Long $_{\text {sat }}-$ Long $\left._{\mathrm{t}}\right)$ and $\mathrm{y}_{\text {sat }}$ $=\mathrm{R}\left(\right.$ Lat $\left._{\text {sat }}\right) \cdot \sin \left(\gamma_{\text {sat }}\right) \cdot \sin \left(\right.$ Long $_{\text {sat }}-$ Long $\left._{\mathrm{t}}\right)$

Thus, we have: $\overrightarrow{\mathrm{W}_{\text {sat }, \perp}}\left\{\cos \left(\operatorname{Long}_{\text {sat }}-\operatorname{Long}_{t}\right), \sin \left(\operatorname{Long}_{\text {sat }}-\operatorname{Long}_{t}\right), \frac{a^{2}}{b^{2}} \frac{z_{\text {sat }}}{X_{\text {sat }}}\right\} \cdot \frac{1}{\sqrt{1+\left[\frac{a^{2} \cdot z_{\text {sat }}}{b^{2} \cdot X_{\text {sat }}}\right]^{2}}}$

It implies: $\quad-\overrightarrow{\mathrm{OS}}=\overrightarrow{\mathrm{Os}}+\left\{\mathrm{H}_{\mathrm{sat}} \cdot \sin \left(\gamma_{\text {sat }}^{*}\right) \cdot \cos \left(\right.\right.$ Long $_{\text {sat }}-$ Long $\left._{t}\right), \mathrm{H}_{\mathrm{sat}} \cdot \sin \left(\gamma_{\text {sat }}^{*}\right) \cdot \sin \left(\right.$ Long $_{\text {sat }}-$ Long $\left.\left._{t}\right), \mathrm{H}_{\mathrm{sat}} \cdot \cos \left(\gamma_{\text {sat }}^{*}\right)\right\}$

This allows one to compute the incidence angle $\alpha$, the sensor off-nadir angle $\beta$ and the satellite azimuth $\phi_{\text {sat }}$ in the local system:

$$
\begin{aligned}
& \cos (\alpha)=\frac{\overrightarrow{\mathrm{TS}} \cdot \overrightarrow{\mathrm{W}_{\mathrm{t}, \perp}}}{\|\overrightarrow{\mathrm{TS}}\| \cdot\left\|\overline{\mathrm{W}}_{\mathrm{t}, \perp}\right\|} \Rightarrow \alpha=\operatorname{acos}\left(\frac{\overrightarrow{\mathrm{TS}} \cdot \overrightarrow{\mathrm{W}_{\mathrm{t}, \perp}}}{\|\overrightarrow{\mathrm{TS}}\| \cdot\left\|\overline{\mathrm{W}}_{\mathrm{t}, \perp}\right\|}\right) \text { with } \alpha \in\left[\begin{array}{ll}
0 & 90^{\circ}
\end{array}\right] \text { and } \overrightarrow{\mathrm{TS}}=\overrightarrow{\mathrm{OS}}-\overrightarrow{\mathrm{OT}} \\
& \cos (\beta)=\frac{\overrightarrow{\mathrm{TS}} \cdot \overrightarrow{\mathrm{W}_{\mathrm{sat}, \perp}}}{\|\overrightarrow{\mathrm{TS}}\| \cdot\left\|\overline{\mathrm{W}}_{\mathrm{sat}, \perp}\right\|} \Rightarrow \beta=\operatorname{acos}\left(\frac{\overrightarrow{\mathrm{TS}} \cdot \overrightarrow{\mathrm{W}_{\text {sat }, \perp}}}{\|\overrightarrow{\mathrm{TS}}\| \cdot\left\|\overline{\mathrm{W}}_{\text {sat }, \perp}\right\|}\right) \text { with } \beta \in\left[\begin{array}{ll}
0 & 90^{\circ}
\end{array}\right] \\
& \overrightarrow{\mathrm{W}_{\mathrm{t}, \perp}} \cdot \frac{\overrightarrow{\mathrm{TS}}}{\|\overrightarrow{\mathrm{TS}}\|}=-\sin (\alpha) \cdot \cos \left(\varphi_{\mathrm{sat}}\right) \Rightarrow \varphi_{\mathrm{sat}}=\operatorname{acos}\left(-\overrightarrow{\mathrm{W}_{\mathrm{t}, \perp}} \cdot \frac{\overrightarrow{\mathrm{TS}}}{\|\overrightarrow{\mathrm{TS}}\|} \cdot \frac{1}{\sin (\alpha)}\right) \text { with } \varphi_{\mathrm{sat}}=2 \pi-\varphi_{\mathrm{sat}} \text { if } \\
& \text { Long }_{t}<\text { Long }_{\text {sat }}
\end{aligned}
$$

\section{References}

Albinet C. (2008). Modélisation 3D des flux et du bilan d'énergie des zones urbaines Modélisation des échanges d'énergie des milieux urbains. M2 report. Paul Sabatier University, Toulouse, France. 57p.

Barbier, N.; Couteron, P.; Proisy, C.; Yadvinder, M. \& Gastellu-Etchegorry, J-P. (2010). The variation of apparent crown size and canopy heterogeneity across lowland Amazonian forests. Global Ecology and Biogeography, DOI: 10.1111/j.14668238.2009.00493.

Barbier, N.; Couteron, P.; Gastellu-Etchegorry J.P. \& Proisy, C. (2011), Linking canopy images to forest structural parameters: potential of a modeling framework, Annals of Forest Science, DOI 10.1007/s13595-011-0116-9

Berk, A.; Bernstein, L.S. \& Robertson, D.C. (1989). MODTRAN: A Moderate Resolution Model for LOWTRAN 7, GL-TR-89-0122, Geophys. Lab., Bedford, MA, USA $38 \mathrm{pp}$.

Gascon, F. (2001). Modélisation Physique d'Images de Télédétection Optique. PhD Thesis. Université Paul Sabatier, Toulouse, France.

Gastellu-Etchegorry, J.P.; Demarez, V.; Pinel V. \& Zagolski F. (1996). Modeling radiative transfer in heterogeneous 3-D vegetation canopies, Remote Sensing of Environment, 58: 131-156. 
Gastellu-Etchegorry, J.P.; Guillevic, P.; Zagolski, F.; Demarez, V.; Trichon, V.; Deering, D. \& Leroy, M. (1999). Modeling BRF and radiation regime of tropical and boreal forests - BRF. Remote Sensing of Environment, 68: 281-316.

Gastellu-Etchegorry, J.P.; Martin, E. \& Gascon, F. (2004), DART: a 3-D model for simulating satellite images and surface radiation budget, 2004, International Journal of Remote Sensing, 25 (1): 75-96.

Gastellu-Etchegorry, J.P. (2008). 3D modeling of satellite spectral images - Radiation budget and energy budget of urban landscapes, Meteorology and Atmosphere Physics, Vol. 102, N 3-4, pp187-207

Gastellu-Etchegorry, J.P.; Grau, E.; Rubio, J.; Ueberschlag, A.; Sun, G.; Brut, A.; Cros, J. \& Lauret, N. (2010). 3-D Monte Carlo radiative transfer with DART model - An application to Lidar modeling. Third International Symposium Recent Advances in Quantitative Remote Sensing, 27 September to 1 October 2010. Torrent-Valencia, Spain.

Govaerts, Y. \& Verstraete, M.M. (1998). Raytran: A Monte Carlo ray tracing model to compute light scattering in three-dimensional heterogeneous media. IEEE Transactions on Geoscience and Remote Sensing, 36, 493-505.

Grau, E. (2011). Modélisation 3D optique d'images de télédétection et du bilan radiation des paysages terrestres. PhD thesis. Paul Sabatier University.

Guillevic, P. \& Gastellu-Etchegorry, J.P. (1999). Modeling BRF and radiation regime of tropical and boreal forests - PAR regime. Remote Sensing of Environment, 68: 317340.

Jacquemoud, S. \& Baret, F. (1990). PROSPECT: a model of leaf optical properties spectra, Remote Sensing of Environment, 34(2):75-91.

Kimes, D.S. \& Sellers, P.J. (1985). Inferring hemispherical reflectance of the Earth's surface for global energy budgets from remotely sensed nadir or directional radiance values. Remote Sensing of Environment, 18: 205-223.

Malenovský, Z.; Martin, E.; Homolová, L.; Gastellu-Etchegorry, J.-P.; Zurita-Milla, R.; Schaepman, M.E.; Pokorný, R.; Clevers, J.G.P.W. \& Cudlín, P. (2008). Influence of woody elements of a Norway spruce canopy on nadir reflectance simulated by the DART model at very high spatial resolution. Remote Sensing of Environment. 112:1-18.

Malenovský, Z.; Ufer, C.; Lhotakova, Z.; Clevers, J.G.P.W.; Schaepman, M.E.; Albrechtova, J. \& Cudlin, P. (2006). A new hyperspectral index for chlorophyll estimation of a forest canopy: Area under curve normalised to maximal band depth between 650725 nm, EARSeL eProceedings 5 (2). p. 161 - 172.

Malenovský, Z.; Martin, E.; Homolova, L.; Pokorny, R.; Schaepman, M.E.; Gastellu-Etchegorry, J.-P.; Zurita Milla, R.; Clevers, J.G.P.W. \& Cudlin, P. (2005). Influence of forest canopy structure simulated using the Discrete Anisotropic Radiative Transfer (DART) model on the retrieval of spruce stand LAI. In: 9th International Symposium on Physical Measurements and Signatures in Remote Sensing (ISPMSRS), Beijing, 17-19 October 2005. Beijing: ISPRS WG VII/1, p. 3. 
Martin, E. (2006). DART: Modèle 3D Multispectral et Inversion d'Images Optiques de Satellite - Application aux couverts forestiers. PhD thesis. Paul Sabatier University.

Masson, V. (2000). A physically-based scheme for the urban energy budget in atmospheric models, Boundary-layer Meteorology, 94:357-397.

Masson, V.; Gomes, L.; Pigeon, G.; Liousse, C.; Pont, V.; Lagouarde, J.-P.; Voogt, J. A.; Salmond, J.; Oke, T. R.; Legain, D.; Garrouste, O.; Lac, C.; Connan, O.; Briottet, X. \& Lachérade, S. (2007). The Canopy and Aerosol Particles Interaction in Toulouse Urban Layer (CAPITOUL) experiment. Meteorology and Atmospheric Physics. , Vol. 102, N 3-4, pp137-157

North, P.R.J. (1996). Three-dimensional forest light interaction model using a Monte Carlo method, IEEE Transactions on Geoscience and Remote Sensing, 34, 946956.

Pinel, V. \& Gastellu-Etchegorry, J.P. (1998). Sensitivity of Texture of High Resolution Images of Forest to Biophysical and Acquisition Parameters. Remote Sensing of Environment. 65: 61-85.

Pinty, B.; Gobron, N.; Widlowski, J.L.; Gerstl, S.A.W.; Vertraete, M.M.; Antunes, M.; Bacour, C.; Gascon, F.; Gastellu-Etchegorry, J.P.; Jacquemoud, S.; North, P.; Qin, W. \& Thompson, R. (2001). Radiation transfer model intercomparaison (RAMI) exercise, Journal of Geophysical Research, 106, D11, 11937-11956.

Pinty, B.; Widlowski, J-L.; Taberner, M.; Gobron, N.; Verstraete, M. M.; Disney, M.; Gascon, F.; Gastellu-Etchegorry, J.-P.; Jiang, L.; Kuusk, A.; Lewis, P.; Li, X.; Ni-Meister, W.; Nilson, T.; North, P.; Qin, W.; Su, L.; Tang, S.; Thompson, R.; Verhoef, W.; Wang, H.; Wang, J.; Yan, G. \& H. Zang (2004). RAdiation transfer Model Intercomparison (RAMI) exercise: Results from the second phase, Journal of Geophysical Research, 109, D06210 10.1029/2003JD004252.

Soux, C.A.; Voogt, J.A. \& Oke, T.R. (2004). A model to calculate what a remote sensor 'sees' of an urban surface, Boundary Layer Meteorology, 111:109-132.

Thompson, R.L. \& Goel, N.S. (1998). Two models for rapidly calculating bidirectional reflectance: Photon spread (ps) model and statistical photon spread (sps) model. Remote Sensing Reviews, 16, 157-207.

Ueberschlag, A. (2010). Etude des couverts forestiers par inversion de formes d'onde Lidar à l'aide du modèle de transfert radiatif DART, XYZ, 126: 22-26.

Voogt, J.A. \& Oke, T.R. (1998). Effects of urban surface geometry on remotely sensed surface temperature, Int. J. Remote Sensing, 19: 895-920.

Voogt, J.A. \& Oke, T.R. (2003). Thermal remote sensing of urban climates, Remote Sensing of Environment, 86:370-384.

Widlowski, J.L.; Taberner, M.; Pinty, B.; Bruniquel-Pinel, V.; Disney, M.; Fernandes, R.; Gastellu-Etchegorry, J-P.; Gobron, N.; Kuusk, A.; Lavergne, T.; Leblanc, S.; Lewis, P. E.; Martin, E.; Mottus, M.; North, P. R. J.; Qin, W.; Robustelli, M.; Rochdi, N.; Ruiloba, R.; Soler, C.; Thompson, R.; Verhoef, W.; Verstraete, M.M. \& Xie, D. (2007). The third RAdiation transfer Model Intercomparison (RAMI) exercise: Documenting progress in canopy refectance models, J. Geophysical Research, 112, D09111, doi: 10.1029/2006JD007821 
Widlowski, J-L; Robustelli, M.; Disney, M.; Gastellu-Etchegorry, J.-P.; Lavergne, T.; Lewis, P.; North, P.R.J.; Pinty, B.; Thompson, R. \& Verstraete, M.M. (2008). The RAMI Online Model Checker (ROMC): A web-based benchmarking facility for canopy reflectance models, Remote Sensing of Environment, 112:1144-1150. 


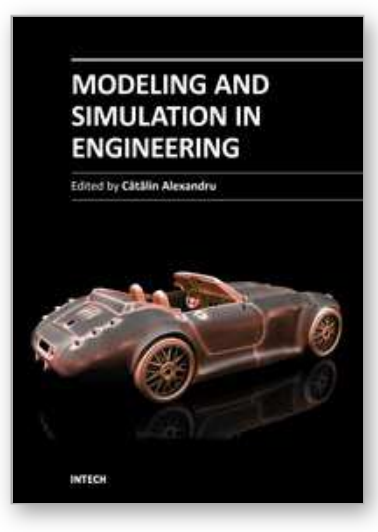

\author{
Modeling and Simulation in Engineering \\ Edited by Prof. Catalin Alexandru
}

ISBN 978-953-51-0012-6

Hard cover, 298 pages

Publisher InTech

Published online 07, March, 2012

Published in print edition March, 2012

This book provides an open platform to establish and share knowledge developed by scholars, scientists, and engineers from all over the world, about various applications of the modeling and simulation in the design process of products, in various engineering fields. The book consists of 12 chapters arranged in two sections (3D Modeling and Virtual Prototyping), reflecting the multidimensionality of applications related to modeling and simulation. Some of the most recent modeling and simulation techniques, as well as some of the most accurate and sophisticated software in treating complex systems, are applied. All the original contributions in this book are jointed by the basic principle of a successful modeling and simulation process: as complex as necessary, and as simple as possible. The idea is to manipulate the simplifying assumptions in a way that reduces the complexity of the model (in order to make a real-time simulation), but without altering the precision of the results.

\title{
How to reference
}

In order to correctly reference this scholarly work, feel free to copy and paste the following:

J.P. Gastellu-Etchegorry, E. Grau and N. Lauret (2012). DART: A 3D Model for Remote Sensing Images and Radiative Budget of Earth Surfaces, Modeling and Simulation in Engineering, Prof. Catalin Alexandru (Ed.), ISBN: 978-953-51-0012-6, InTech, Available from: http://www.intechopen.com/books/modeling-and-simulationin-engineering/dart-model-remote-sensing-images-radiative-budget-and-energy-budget-of-earth-surfaces

\section{INTECH}

open science | open minds

\author{
InTech Europe \\ University Campus STeP Ri \\ Slavka Krautzeka 83/A \\ 51000 Rijeka, Croatia \\ Phone: +385 (51) 770447 \\ Fax: +385 (51) 686166 \\ www.intechopen.com
}

\author{
InTech China \\ Unit 405, Office Block, Hotel Equatorial Shanghai \\ No.65, Yan An Road (West), Shanghai, 200040, China \\ 中国上海市延安西路65号上海国际贵都大饭店办公楼 405 单元 \\ Phone: +86-21-62489820 \\ Fax: $+86-21-62489821$
}


(C) 2012 The Author(s). Licensee IntechOpen. This is an open access article distributed under the terms of the Creative Commons Attribution 3.0 License, which permits unrestricted use, distribution, and reproduction in any medium, provided the original work is properly cited. 